\title{
Spectroscopic studies of the mechanism of reversible photodegradation of 1-substituted aminoanthraquinone-doped polymers
}

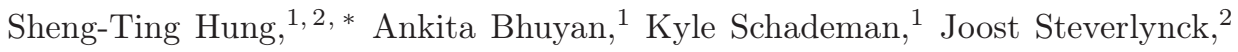 \\ Matthew D. McCluskey, ${ }^{1}$ Guy Koeckelberghs, ${ }^{2}$ Koen Clays, ${ }^{1,2}$ and Mark G. Kuzyk ${ }^{1}$ \\ ${ }^{1}$ Department of Physics and Astronomy, Washington State University, Pullman, WA 99164-2814 \\ ${ }^{2}$ Department of Chemistry, University of Leuven, Leuven, Belgium B-3001
}

(Dated: November 11, 2015)

\begin{abstract}
The mechanism of reversible photodegradation of 1-substituted aminoanthraquinones doped into poly(methyl methacrylate) and polystyrene is investigated. Time-dependent density functional theory is employed to predict the transition energies and corresponding oscillator strengths of the proposed reversibly- and irreversibly-damaged dye species. Ultraviolet-visible and Fourier transform infrared (FTIR) spectroscopy are used to characterize which species are present. FTIR spectroscopy indicates that both dye and polymer undergo reversible photodegradation when irradiated with a visible laser. These findings suggest that photodegradation of 1-substituted aminoanthraquinones doped in polymers originates from interactions between dyes and photoinduced thermally-degraded polymers, and the metastable product may recover or further degrade irreversibly.
\end{abstract}

\section{INTRODUCTION}

Organic materials have a broad range of applications such as high-resolution fluorescence microscopy $\sqrt{1}[7]$, second harmonic generation (SHG) microscopy [8-12], dye sensitized and polymer solar cells [13 17, solid state dye/organic lasers 18 20, and organic light emitting diodes [21, 22], to name a few. Photostability of organic compounds and polymers is often a requirement for applications incorporating light-matter interaction [2 4, 6, 8, 18 20, 23 30]. When a material undergoes photodegradation, its characteristic properties deteriorate over time, which is referred to as decay; the reverse change in the characteristic properties of the material is referred to as recovery. Though photodegradation is often irreversible, the recovery process has been observed from a large variety of materials, typically involving polymers and often together with dyes, with various experimental techniques when the photodegraded materials are kept in dark for a long enough time, typically hours to days [30-44].

Amplified spontaneous emission (ASE) of disperse orange 11 (DO11) doped in poly(methyl methacrylate) (PMMA) bulk sample was observed to fully recover in the dark about 40 hours after photodegradation when irradiated with a $532 \mathrm{~nm}$ second harmonic Nd:YAG picosecond laser 33. This self-healing phenomenon was also observed in various anthraquinone derivatives doped in PMMA and polystyrene (PS) thin films [41, 42] and DO11 doped in MMA-styrene copolymers thin films 42, 45] probed with transmittance image microscopy and ASE. The photodegraded thin film samples are often observed to recover partially, which suggests there exists both reversible and irreversible photodegradation. The lack of evidence for linear dichroism during photodegradation measurements eliminates orientational hole burning as the mechanism causing reversible photodegra- dation [46]. Spatially resolved ASE and fluorescence [47], spatial imaging [48] and ultraviolet-visible (UV-Vis) spectroscopy [49] studies indicate that diffusion/back diffusion is not responsible for reversible photodegradation. While some phenomenological kinetic models have been proposed based on quantitative studies of reversible photodegradation in dye-doped polymer (dye/polymer) samples including AF455/PMMA and DO11/PMMA, a decade of research using various experimental techniques [38, 42, 46, 50 54], they have failed to elucidate the underlying mechanism.

Several hypotheses of the mechanism responsible for reversible photodegradation in DO11/PMMA have been proposed, including intramolecular proton transfer and dimer formation [46], twisted intramolecular charge transfer [55], and domain-assisted reversible photodegradation [51, 56, 57], none have been experimentally proven. These hypotheses, together with anion formation [58, 59] and protonation [60, 61] of dye molecules observed in similar systems, have been investigated and the results suggest that they are unlikely responsible for reversible photodegradation of 1-substituted aminoanthraquinone derivatives doped in PMMA and PS [49].

This study aims to understand the underlying mechanism of reversible and irreversible photodegradation of 1-substituted aminoanthraquinone-doped polymers by combining Gel permeation chromatography (GPC), time-dependent density functional theory (TD-DFT) calculations, UV-Vis spectroscopy and FTIR spectroscopy to characterize chemical species and changes in molecular structures during photodegradation and recovery. Most research reported in the literature on 1substituted aminoanthraquinone derivatives focus on 1-aminoanthraquinone (1AAQ) instead of DO11, the molecule studied most extensively in our laboratory. The fact that reversible photodegradation has been observed in both 1AAQ and DO11 doped in PMMA matrices suggests that photoinduced reactions between $1 \mathrm{AAQ}$ or 
DO11 and the polymer host are the same process [49]. Therefore, both 1AAQ and DO11 are utilized in this study and the results obtained from each molecule are assumed to be applicable to each other.

\section{BACKGROUND}

Anthraquinone exhibits a weak optical absorption band at $405 \mathrm{~nm} \mathrm{60,62],} \mathrm{with} \mathrm{an} \mathrm{extinction} \mathrm{coeffi-}$ cient about $60 \mathrm{~cm}^{-1} \mathrm{M}^{-1}$ (in methanol) which is often undetected [60]. Aminoanthraquinones, however, possess moderate to strong absorption bands in the visible regime, which are absent in anthraquinone, and have been assigned to intramolecular charge transfer (ICT) between the amine group and the carbonyl groups [63, 64]. For example, DO11 dissolved in MMA is observed to show an absorption peak at $471 \mathrm{~nm}$ with an extinction coefficient of $8.043 \times 10^{3} \mathrm{~cm}^{-1} \mathrm{M}^{-1}$. The calculated electron density of $1 \mathrm{AAQ}$ is also observed to increase in the unsubstituted ring and in the carbonyl groups in the first excited state relative to the ground state [60]. This indicates that the carbonyl groups are not the only electron acceptors [60]. This observation is consistent with the results reported by Inoue et al. that the calculated electron density of $1 \mathrm{AAQ}$ of the first excited state is increased in the carbonyl groups, the center ring and the unsubstituted ring, though they only mentioned the carbonyl groups [63].

Photocycloaddition of $1 \mathrm{AAQ}$ to olefines, including styrene, was observed with visible light irradiation provided by an optically filtered $(\lambda>420 \mathrm{~nm}) 300 \mathrm{~W}$ highpressure mercury lamp at $0{ }^{\circ} \mathrm{C}$ [65, 66]. In this photochemical reaction, the carbonyl group adjacent to the amine group of $1 \mathrm{AAQ}$ reacts with a diene (or olefine) under exposure of visible light to form a corresponding oxetane. The structures of some reaction products were confirmed by IR, NMR, and mass spectrometry [65, 66].

Although there was no photocycloaddition observed between 1AAQ and monoenes [65, 66], the reason was not mentioned. A possible explanation is that the light source used in the experiment did not provide enough intensity to show a measurable reaction rate, but if the solution is irradiated with a higher-powered light source such as a laser, the reaction rate might be increased above the detection threshold. Another hypothesis is that the visible light source did not provide enough energy to overcome the activation energy for photocycloaddition of $1 \mathrm{AAQ}$ with monoenes at $0{ }^{\circ} \mathrm{C}$. However, when irradiating the solution with a more intense light source such as a laser, the energy density in the vicinity of the irradiated dye molecules might be temporarily high due to nonradiative relaxation of photo-excited dye molecules, thus, overcoming the activation energy of photocycloaddition. Thus, photocycloaddition may occur between 1substituted aminoanthraquinones and olefines in general, including monoenes such as methyl methacrylate (MMA) when exposed to a laser.

Photocycloaddition was proposed to involve excited complex (exciplex) formation between an excited ICT state of $1 \mathrm{AAQ}$ and an olefine 67. The photocycloaddition was unaffected by oxygen, and the reaction products were unstable in an environment of carbon dioxide, acid, light, and heat [65, 66]. Most importantly, the reaction products were found to gradually decompose into other compounds including $1 \mathrm{AAQ}$ itself at 30 ${ }^{\circ} \mathrm{C}$ [65]. The return of $1 \mathrm{AAQ}$ from the photocycloaddition products could be the recovery process observed in 1AAQ-doped polymers if photocycloaddition occurs between $1 \mathrm{AAQ}$ and the polymer hosts or fragments of thermally degraded polymers, including depolymerized monomers due to locally accumulated heat via nonradiative relaxation of excited dye molecules.

Thermal degradation of polymers has been studied extensively for several decades, and the dominant products of thermal degradation of PS and PMMA are known to be their monomers, styrene and MMA, respectively 68 70]. Mechanisms of thermal degradation such as depolymerization, scission of side chains, and dissociation of the polymer backbones take place depending on the environment, temperature, molecular weight, chain end groups, chain configuration, polymerization condition etc. 6882. As such, the activation energy of thermal degradation varies widely. It is generally found to be between $1.87 \mathrm{eV}$ and $3.34 \mathrm{eV}$ for PS in an inert atmosphere or vacuum 71], and from $1.23 \mathrm{eV}$ to $3.55 \mathrm{eV}$ for PMMA in an inert atmosphere [70, 72 74, 77, 79 81]. The photon energies of lasers used in this study are $2.33 \mathrm{eV}$ and $2.54 \mathrm{eV}$, which are within the reported range of activation energies for thermal degradation of PS and PMMA.

The fluorescence quantum yield of $1 \mathrm{AAQ}$ in several organic solvents was reported to be less than $10 \%$ [83, 84]. Thus, most of the photon energy absorbed by $1 \mathrm{AAQ}$ molecules is lost via nonradiative relaxation, leading to an accumulation of heat centered on the $1 \mathrm{AAQ}$ molecules. This local buildup of heat can cause thermal degradation of nearby polymer chains.

Photoinduced damage in dye-doped polymer matrices has been studied in various systems for different applications 85 94]. Sensitized photodegradation and photooxidation of polymers can be induced by photoinitiators, in which polymer degradation or oxidation can be initiated by free radicals originating from photodegradation of sensitizers; or by photosensitizers, in which excited sensitizers transfer energy to the polymer or oxygen to initiate photodegradation or photooxidation [85]. Studies on photooxidation or photodegradation of various sensitized polymers have been reported including sensitized PS 85 88] and sensitized PMMA [89, 90]. Laser ablation of polymers can be induced with the assistance of photosensitizers using visible lasers at wavelengths of $351 \mathrm{~nm}$ [91], $488 \mathrm{~nm}$ 92], and $532 \mathrm{~nm}$ [93]. Fukumura 
et al. proposed that the photon energy absorbed by anthracene, the sensitizer, is converted into thermal energy in PS, the polymer host, causing thermal decomposition [91]. In a study of photodestruction of a solid-state dye laser composed of Rh6G-chloride dye doped in a modified PMMA gain medium, Popov attributed photobleaching of excited-state dye molecules to the permanent degradation of the lasing efficiency, and assigned the formation of carbon (char) in the polymer matrix to the polymer decomposition due to accumulated heat transferred from photoexcited dye molecules via direct vibrations and nonradiative relaxation of their singlet levels [94].

\section{Hypothesis}

Given the above reasoning that is guided by observations, we propose that a series of photothermally-induced chemical reactions (PTCR) between dye and polymer is a potential mechanism responsible for reversible and irreversible photodegradation of $1 \mathrm{AAQ}$ (and DO11) doped in PMMA and PS as follows:

1AAQ (and DO11) undergoes ICT when excited with visible light, and the absorbed photon energy can be transferred to nearby polymer chains via nonradiative relaxation of the excited ICT singlet states. The transferred energy locally heats the polymer around the excited dye molecules, which leads to thermal degradation of the polymer including depolymerization, scission of side chains, and dissociation of polymer backbones. Since monomers are the major products of thermally degraded polymers (PS and PMMA), an excited dye molecule can undergo photocycloaddition with a monomer in its vicinity to form the reversibly photodegraded dye species. In addition to monomers, there are other decay products such as $\cdot \mathrm{CH}_{3}, \cdot \mathrm{COOCH}_{3}$, 'phenyl, and polymer chain radicals etc., which can attack ground- and excitedstate dye molecules and reversibly-damaged dye species causing irreversible damage to dye molecules. While reversibly-damaged dye species may gradually recover back to the original dye molecule with a monomer left behind in the polymer matrix, it may also further decompose to an irreversibly-damaged dye species or dye radical or other fragments of radicals. Thus, the "recovered" and thermally degraded monomers and radical fragments can react with each other or with decomposed polymer fragments, polymer chains and unsaturated polymer chain ends causing recovery of the polymer or changes in the polymer including the formation of small molecular weight polymer chains, cross linked polymer chains, and perhaps new species of polymer segments and chains.

The PTCR hypothesis is illustrated with D011/PMMA in Figure 1. In this mechanism, dye undergoes (photo)degradation after the thermal degradation of polymer chains. The reversible degradation of dye requires at least two photons initially, but there can be multiple monomers available in the vicinity of a dye molecule once the degradation of the polymer takes place, so the reversible degradation does not necessarily require two photons. On the other hand, the irreversible degradation of dye may be caused by radicals produced from at least one-photon-induced thermal degradation of the polymer.

(1)

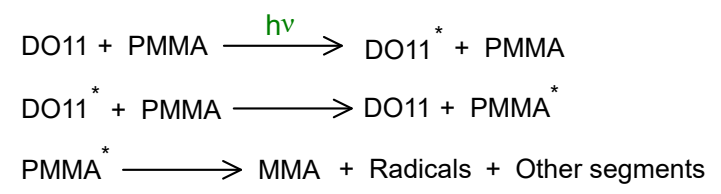

(4)
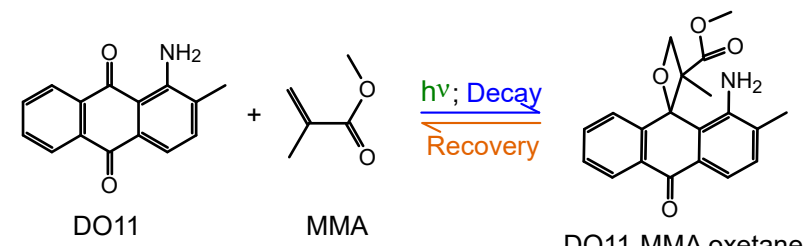

(4')

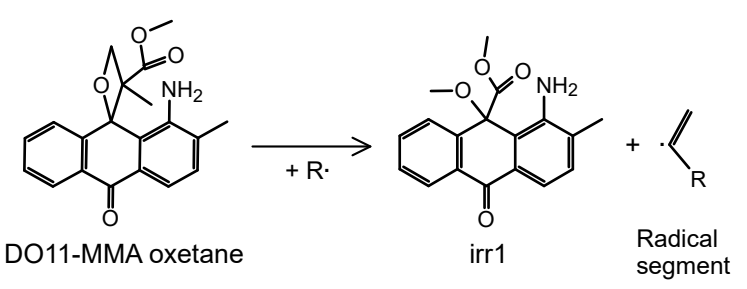

(4")

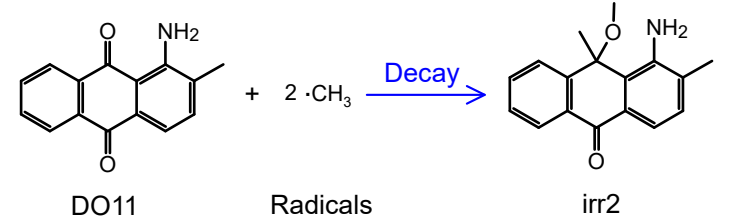

FIG. 1: Reversible and irreversible photodegradation of DO11/PMMA. The asterisk indicates photoexcited DO11 or heated PMMA through nonradiative energy transfer from excited DO11. Reversible and irreversible degradation in DO11 starts after thermal degradation of

PMMA (step (3)).Non-radical segments can also undergo thermal degradation similar to step (2) and (3) resulting in radicals. The reversibly-damaged species may undergo recovery (back reaction of step (4)) or decompose into irreversibly-damaged species and radical segments (step $\left.\left(4^{\prime}\right)\right)$. "irr1" and "irr2" are possible irreversibly-damaged dye species illustrated in Figure2, There can be other irreversibly-damaged dye species depending on DO11's nearby radicals and polymer segments.

Reversibly-damaged DO11 in PMMA and PS is proposed to be oxetanes as shown in Figure 2(a). Irreversibly-damaged DO11 in PMMA and PS are illustrated in Figure 2(b) but other species may form due to the various radicals formed upon thermal degradation of polymer chains. The important point is that the carbonyl group adjacent to the amine group is damaged, and 
the carbon and oxygen atoms singly bond to thermallydegraded polymer fragments or polymer chains as will be rationalized later in the discussion.
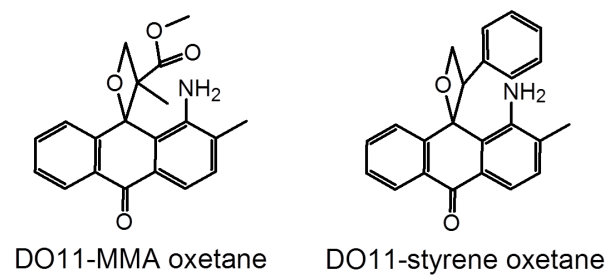

(a)
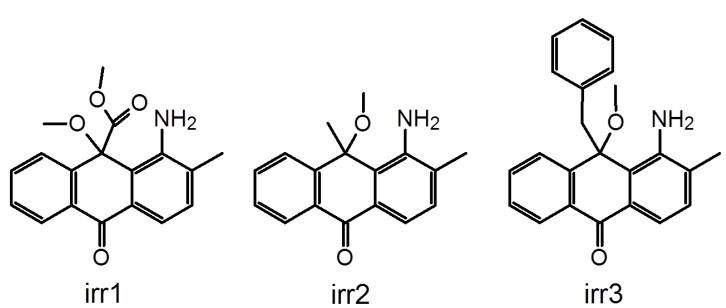

(b)

FIG. 2: (a) Proposed reversibly-damaged DO11 biproducts made by photocycloaddition with MMA (left) and styrene (right). (b) Illustration of possible irreversibly-damaged DO11 species.

\section{COMPUTATIONAL METHOD}

Ultraviolet-visible (UV-Vis) spectra of various organic molecules including anthraquinone derivatives have been calculated using TD-DFT and the results are found to be in good agreement with the observed spectra if the appropriate basis set of wavefunctions and functionals are chosen [95 99]. In order to obtain a qualitative estimate of the absorption spectra of possible photodegraded dye molecules within a reasonable computing time, a method that produces reasonably good predictions for visible spectra of anthraquinone derivatives is adopted [95] in this study.

Gaussian 03 was used to perform the TD-DFT calculations. Geometry optimization of pristine DO11 and all possible damaged DO11 species in Figure 2 were carried out with the $6-31 \mathrm{G}(\mathrm{d}, \mathrm{p})$ basis set and the B3LYP functional for each species in vacuum. TD-DFT calculations were carried out with the optimized ground state geometry using the same basis set and functional, and the polarizable continuum model (PCM) was used to account for solvent effects. Photodegradation experiments were performed in PS and PMMA polymer matrices that have dielectric constants of 2.6 and 2.6-3.1 [100], respectively, which are somewhat close to toluene's value of 2.38 [100]. Thus, toluene was selected as the PCM solvent in
TD-DFT calculations.

\section{EXPERIMENTAL METHOD}

\author{
Sample preparation
}

1AAQ and 1-amino-2-methylanthraquinone (DO11) with a purity of $97 \%$ and $95 \%$, respectively; and methyl methacrylate (MMA) and styrene were purchased from Aldrich. MMA and Styrene were purified using two column flasks (one for each) filled with alumina powder to remove the inhibitors that prevent monomers from polymerization. Commercially available PMMA (MW $=120,000)$ purchased from Aldrich was also used in this study.

Thin-film samples prepared from monomers To make dye-doped PMMA samples, dye and purified MMA monomer were mixed in proportions to obtain the desired dye concentration and were sonicated for 30 minutes. After sonication, both butanethiol (chain transfer agent) and tert-butyl peroxide (initiator) were added to the solutions in the proportion of $3.3 \mu \mathrm{l}$ per ml MMA, and were sonicated for another 30 minutes. The sonicated solutions were filtered with $0.2 \mu \mathrm{m}$ syringe filters and placed in an oven at $95{ }^{\circ} \mathrm{C}$ to initiate the polymerization reaction for at least 2 days resulting in dye-doped polymers. An appropriate volume of polymerized sample was pressed between two $2.5 \mathrm{~cm} \times 2.5 \mathrm{~cm}$ glass substrates at $140{ }^{\circ} \mathrm{C}$ (well above the glass transition temperature where the polymer flows) with an uniaxial pressure of $110 \pm 10 \mathrm{psi}$ for 90 minutes to make a thin film. The pressure was gradually reduced while the sample was cooling at an average rate about $1.5{ }^{\circ} \mathrm{C} / \mathrm{min}$.

For dye-doped PS samples, the same procedure as described above was used, but with $4.2 \mu \mathrm{l}$ of initiator added to $1 \mathrm{ml}$ of styrene. The filtered solutions were placed in an oven at $95{ }^{\circ} \mathrm{C}$ for 4 days for complete polymerization. The glass transition temperature of dye-doped PS samples is lower than dye-doped PMMA samples, so the temperature for pressing thin films was reduced to 120 ${ }^{\circ} \mathrm{C}$.

Thin-film samples obtained by this method have thicknesses in the range of $20-120 \mu \mathrm{m}$ depending on the amount of polymerized sample pressed between the glass slides.

Thin-film samples prepared from PMMA Appropriate amounts of dye and PMMA in the desired ratio were dissolved into a solution composed of $33 \% \gamma$ butyrolactone and $67 \%$ propylene glycol methyl ether acetate (PGMEA) with 10\% solute and $90 \%$ solvent by weight. The solution was stirred for 2 to 3 days to dissolve the dye and polymer, then filtered with a $0.2 \mu \mathrm{m}$ syringe filter. The filtered solution was then spin-coated on $2.5 \mathrm{~cm} \times 2.5 \mathrm{~cm}$ glass substrates at $600 \mathrm{rpm}$ for 90 seconds to make films for linear absorption spectroscopy 
measurements. The filtered solution was also spin-coated on a $2.5 \mathrm{~cm} \times 2.5 \mathrm{~cm}$ silicon wafer at $3000 \mathrm{rpm}$ for 50 seconds to make films for performing FTIR experiments. All spin-coated samples were stored in a vacuum oven at $100{ }^{\circ} \mathrm{C}$ for 90 minutes; then, the heater was turned off and the samples were kept in vacuum over night.

The thickness of the films made by spin-coating on a glass slide is about $0.6 \mu \mathrm{m}$ estimated by the absorbance of the 1AAQ/PMMA thin film [49]. The thickness of films made by spin-coating on a silicon substrate is not measured, but based on the fact that the spin speed was 5 times faster than the sample spin-coated on a glass slide the film's thickness is expected to be less than $0.6 \mu \mathrm{m}$.

\section{GPC}

PMMA purchased from Aldrich and DO11/PMMA polymerized from DO11 dissolved in MMA monomers with concentration $9 \mathrm{~g} / \mathrm{L}$ were used in the GPC experiment. MMA and DO11 were also tested with GPC as a control. MMA, DO11, PMMA and DO11/PMMA samples were dissolved in Tetrahydrofuran (THF), filtered through a $20 \mu \mathrm{m}$ filter and injected. A Shimadzu 10A apparatus with a PLgel $5 \mu \mathrm{m}$ mixed-D type column and a refractive index detector (RID) and UV-Vis spectrometer were used as detectors.

\section{UV-Vis spectroscopy}

The setup for the UV-Vis spectroscopy experiments is schematically shown in Figure 3(a). A continuous wave (cw) argon ion laser providing the pump beam at a wavelength of $514 \mathrm{~nm}$ and a cw solid state laser providing the other pump beam at a wavelength of $532 \mathrm{~nm}$ were used to induce photodegradation. Two light sources were used for absorption measurements: an Ocean Optics PX2 Xenon pulsed lamp and an Ocean Optics LS1 tungsten halogen lamp. The spectrometer was an Ocean Optics Model SD2000. The angle between the cw pump beam and the white light path was about $15^{\circ}$. The $532 \mathrm{~nm}$ pump laser beam passed a $5 \times$ beam expander to make a $1 / \mathrm{e}$ diameter of $7.5 \mathrm{~mm}$. The argon ion laser beam was not expanded and the 1/e diameter of $514 \mathrm{~nm}$ was $1.01 \mathrm{~mm}$. The white light was focused to a diameter of $0.6 \mathrm{~mm}$. The white light probe was centered on the $\mathrm{cw}$ pump beam at the sample. The sample was mounted on a translation stage, which allowed the reference spectrum to be retaken through air in proper time intervals during recovery to ensure that the change of absorbance is not due to drift of the white light intensity.

While the cw laser was causing photodegradation in the sample, the absorption spectra were recorded in proper time intervals with the pump laser temporarily blocked. After the desired irradiation time for pho- todegradation, the cw laser was turned off and absorption spectra were recorded in preset time intervals to monitor recovery.

The absorption spectra of irreversibly-damaged dye species can be approximated by irradiating the sample for a long enough time so that the absorption spectrum no longer changes. Thus, a DO11/PS sample of concentration $9 \mathrm{~g} / \mathrm{L}$ was irradiated with the $532 \mathrm{~nm}$ wavelength laser at a peak intensity of $35.01 \mathrm{~W} / \mathrm{cm}^{2}$ for 90 minutes, and a DO11/PMMA sample of concentration $9 \mathrm{~g} / \mathrm{L}$ prepared from MMA monomers was irradiated with the 514 $\mathrm{nm}$ wavelength laser at a peak intensity of $34.91 \mathrm{~W} / \mathrm{cm}^{2}$ for 180 minutes to estimate the absorption spectra of irreversibly-damaged dye species.

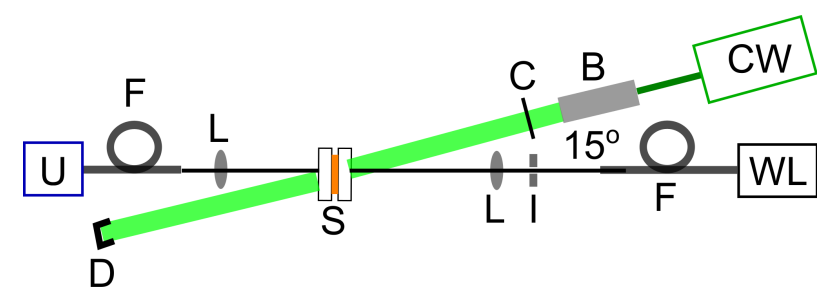

(a)

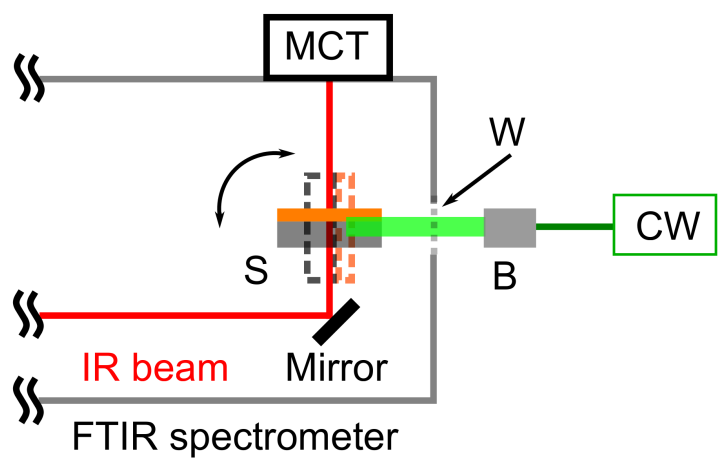

(b)

FIG. 3: (a) UV-Vis spectroscopy setup. (b) FTIR spectroscopy setup. The pump beam is a cw laser and is expanded 5 times in diameter. (CW) CW Laser. (B) $5 \times$ beam expander. (C) Shutter. (D) Beam dump. (F) Optical fiber. (I) Iris. (L) Convex lens. (S) Sample. (U) Spectrometer. (WL) White light source. (W) Quartz window. (MCT) the MCT detector.

\section{FTIR spectroscopy}

IR spectra were obtained from a DA8 Bomen FTIR spectrometer equipped with a water-cooled globar broadband light source (200 to $10000 \mathrm{~cm}^{-1}$ ), a KBr beam splitter (450 to $5000 \mathrm{~cm}^{-1}$ ), and a liquid nitrogen cooled MCT detector $\left(400\right.$ to $5000 \mathrm{~cm}^{-1}$ ). The pressure inside the 
FTIR spectrometer was kept below 0.2 torr throughout the entire experiment. The aperture was set at $10.0 \mathrm{~mm}$, the speed of the moving mirror was $0.5 \mathrm{~cm} / \mathrm{s}$, and the resolution was $4 \mathrm{~cm}^{-1}$. The customized sample holder has 3 holes allowing light to pass and each of them is 5 $\mathrm{mm}$ in diameter, so three spin-coated (dye-doped) polymer samples can be loaded simultaneously. The $532 \mathrm{~nm}$ pump beam generated from a cw solid state laser was expanded with a $5 \times$ beam expander and sent into the sample chamber through a quartz window resulting in a $7.5 \mathrm{~mm}$ diameter pump beam at the sample. The peak intensity of the expanded pump beam was approximately $2.09 \mathrm{~W} / \mathrm{cm}^{2}$. The setup for the FTIR spectroscopy experiments is schematically shown in Figure 3(b). The dye-doped polymer sample can be rotated $90^{\circ}$ for laser irradiation, and rotated back to the original position for taking IR spectra after irradiation. The quartz window was covered and the laser beam was blocked while the IR spectra were taken.

For FTIR experiments, a plain silicon wafer and a PMMA film on a silicon wafer were prepared as controls. A 1AAQ/PMMA film on a silicon wafer was prepared for probing chemical bonds in dye and the host polymer during reversible photodegradation. To minimize the uncertainty, all three samples were fixed on the sample holder and placed in the vacuum chamber for the entire experiment.

All IR spectra were acquired at room temperature. IR spectra taken before irradiation were averaged over 6000 scans, which took about 66 minutes. The 1AAQ/PMMA sample was irradiated for 30 minutes. IR spectra of 1AAQ/PMMA acquired after irradiation were averaged over 1500 scans (about 16 minutes) during the first 400 minutes, 3000 scans (about 32 minutes) for the measurement at the $540^{\text {th }}$ minute, and 6000 scans afterward.

\section{RESULTS AND DISCUSSION}

\section{GPC results}

The PTCR hypothesis suggests that DO11 (and 1AAQ) may undergo reversible photodegradation with monomers. While DO11 dissolved in dimethylformamide (DMF) was observed to undergo irreversible photodegradation 101], DO11 dissolved in styrene and 1AAQ dissolved in MMA have been observed to undergo the same reversible photodegradation as observed in dyedoped polymers [49] which supports the PTCR hypothesis. This indicates that DO11 and DMF do not form a metastable product as does DO11 and MMA or styrene after visible laser irradiation.

Is the reversible photodegradation process observed in a dye-doped polymer due to the residual monomers, or are polymers involved as in the PTCR hypothesis? This hypothesis is tested by running pristine PMMA,

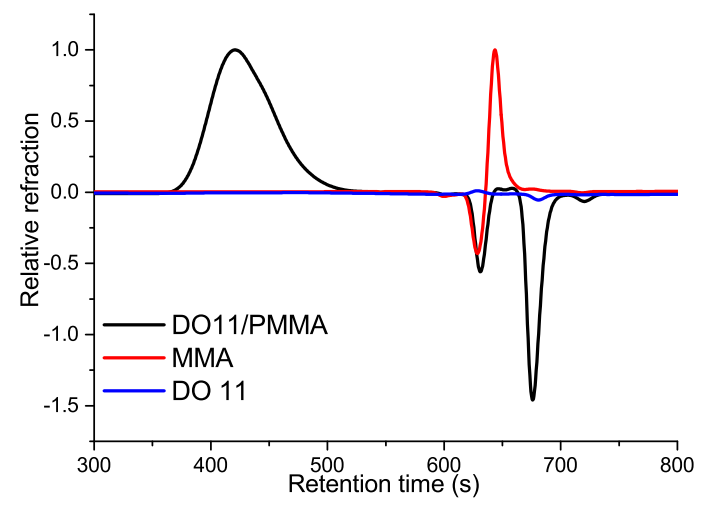

FIG. 4: GPC results detected with RID. No peaks observed before $300 \mathrm{~s}$.

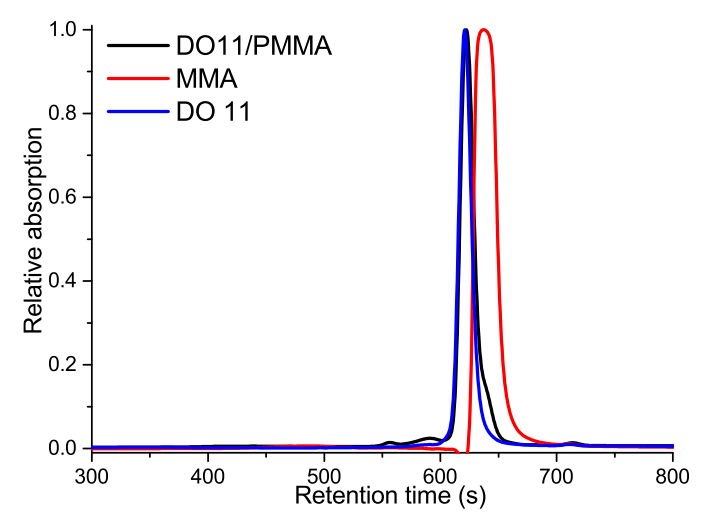

FIG. 5: GPC results detected with UV-Vis spectrometer at $254 \mathrm{~nm}$. No peaks observed before $300 \mathrm{~s}$.

DO11/PMMA, DO11 and MMA monomers through GPC.

MMA is visible in RID and UV-Vis spectrometry. PMMA is only visible in RID, while DO11 is only visible with UV-vis spectrometry. MMA is observed to peak at $644 \mathrm{sec}$ when measured by RID in Figure 4 and 637 sec when measured by UV-Vis spectrometry at $254 \mathrm{~nm}$ as shown in Figure 5. Pristine DO11/PMMA shows no peak at 644 sec measured by RID indicating that no monomers are present in DO11/PMMA, which is confirmed by the UV-vis detector as no peak at $637 \mathrm{sec}$ is observed. However, a peak at 623 sec suggests the presence of a small molecule. This peak overlaps with the signal of DO11. Since this molecule is invisible in RID just as DO11 - this peaks can tentatively be ascribed to the dye. In RID, the peak at $421 \mathrm{sec}$ arises from the polymer. Calibration towards PMMA (in sample DO11/PMMA) results in molar mass $\overline{M_{n}}$ of $9.2 \mathrm{~kg} / \mathrm{mol}$ and dispersity $Đ$ of 2.4. Both measurements indicate that there are no MMA monomers in pristine DO11/PMMA sample. PMMA purchased from Aldrich is also found to contain no monomers from RID measurement. These results indicate that there exist no monomer residues in 
fresh DO11/PMMA that can contribute to the observation of reversible photodegradation.

\section{Computational results}

The absorption spectrum of pristine dye doped in polymer can be measured before the material is damaged and the absorption spectrum of all irreversibly-damaged dye species together can be determined approximately from a measurement after the sample has been irradiated for a long enough time such that the absorption spectrum no longer changes with time. Figure 6 (a) and 7(a) show measurements before irradiation and after a long-time irradiation. However, the absorption spectra of reversibly-damaged dye species cannot be so easily de-

Wavelength $(\mathrm{nm})$

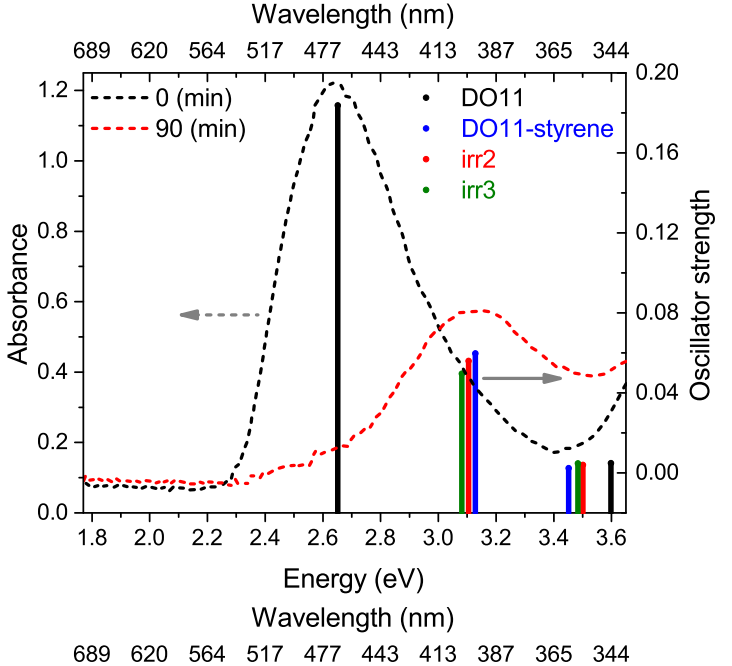

(b)

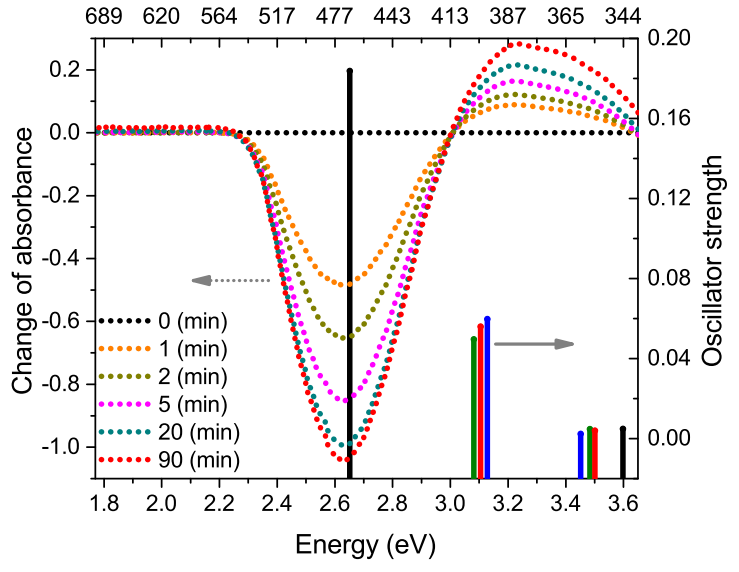

FIG. 6: (a) UV-Vis absorption spectra of pristine DO11/PS and after 90 minutes of irradiation are shown as dashed curves. The oscillator strengths of the proposed degraded species are shown as vertical lines in proportion to their lengths. (b) Change of absorbance during decay relative to the pristine sample (dotted curves) and the oscillator strengths of the proposed degraded species (vertical lines). termined due to the fact that they never appear alone and because the reversibly-damaged dye species recover making their contribution unknown. Nonetheless, isosbestic points found in the change of absorption spectra during photodegradation as shown in Figure 6(b) and 7 (b) indicate that the absorption spectra of the reversiblydamaged dye species are either similar to that of pristine dye or of the irreversibly-damaged dye species in visible regime.

The lowest electronic transition energies of DO11 and all degraded species proposed in Figure 2 obtained using TD-DFT calculations correspond to the transition between the highest occupied molecular orbital (HOMO) and the lowest unoccupied molecular orbital (LUMO). The electron density for HOMO and LUMO of each species is shown in Figure 8 . The calculated electron

(a)

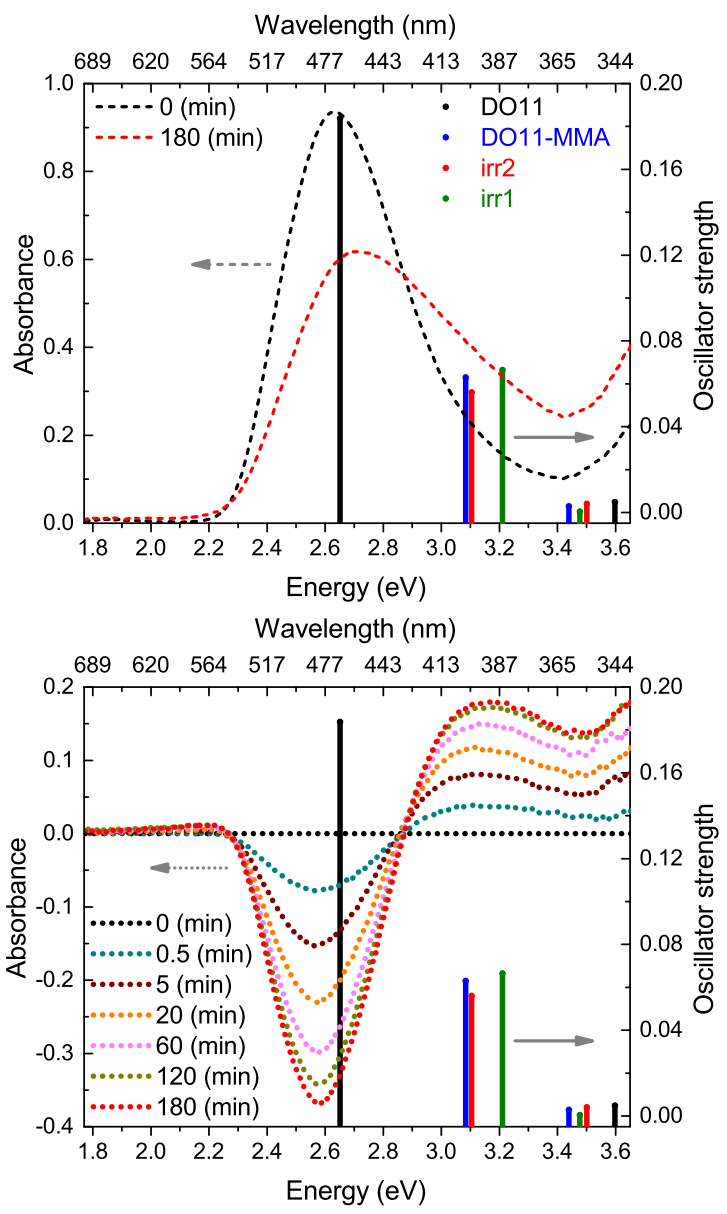

FIG. 7: (a) UV-Vis absorption spectra of pristine DO11/PMMA and after 180 minutes of irradiation are shown as dashed curves. The oscillator strengths of the proposed degraded species are shown as vertical lines in proportion to their lengths. (b) Change of absorbance during decay relative to the pristine sample (dotted curves) and the oscillator strengths of the proposed degraded species (vertical lines). 
density of HOMO-LUMO transition for DO11 agrees with the computational results for aminoanthraquinones in the literature [60, 63] : the amine group is the principal electron donor of the ICT, and the electron acceptors include both carbonyl groups, the center ring and the unsubstituted ring. However, while the amine group remains the principal electron donor of the ICT for all reversibly- and irreversibly-damaged species, the carbonyl group adjacent to the amine group loses its electron accepting ability even though the other electron acceptors are unchanged in their electron accepting ability. Since the ICT is disrupted by the lowered propensity for accepting electrons in the same way for all degraded species, the absorption spectra of reversibly- and irreversibly-damaged species are expected to be similar in visible regime.

Figure 6(a) shows the absorption spectra of pristine and an approximation to irreversibly-damaged DO11/PS. Figure 6(b) shows the change of absorbance during photodegradation. The calculated oscillator strengths and their corresponding excitation energies in visible regime of pristine and reversibly- and irreversiblydamaged DO11 are also plotted in Figure 6. The agree-

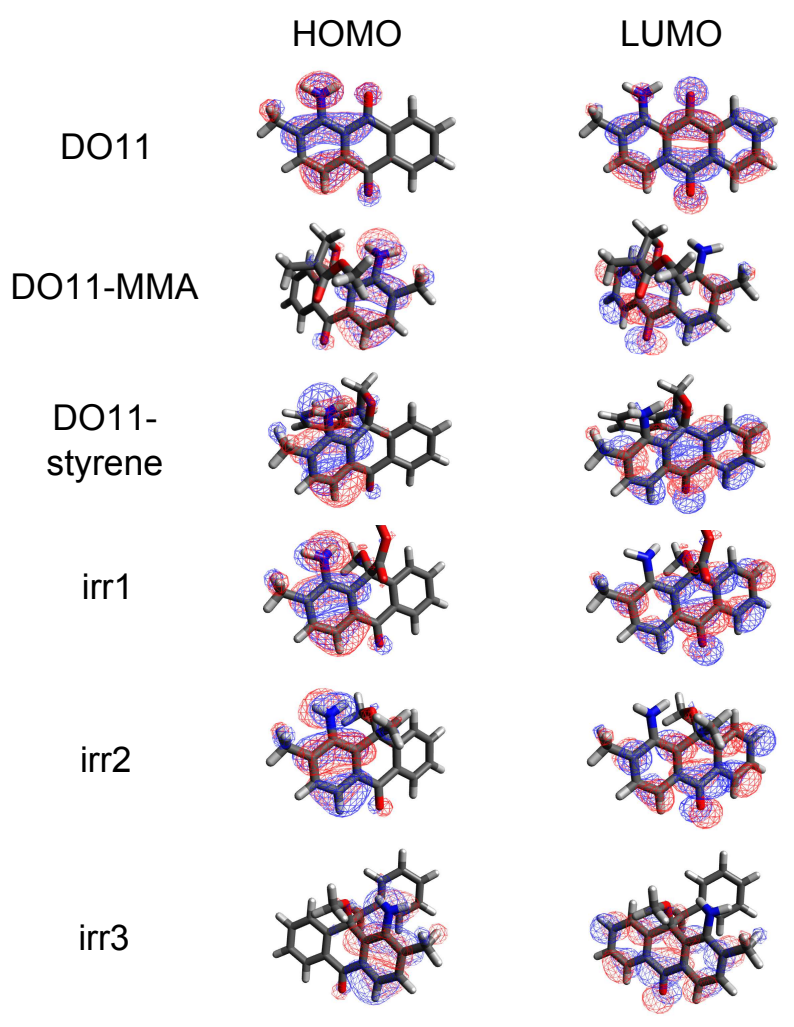

FIG. 8: HOMO and LUMO electron density of DO11 and possible damaged species. Red and blue lobes indicate the electron density with opposite phases in the electron wavefunctions. Colors in molecular structures: black represents the carbon atom, gray the hydrogen atom, red the oxygen atom and blue the nitrogen atom. ment between the experimental and calculated results supports that the ICT is disrupted in the same way for both reversibly- and irreversibly-damaged species. Figure 7 shows that the DO11/PMMA data is not in as good agreement as the DO11/PS data possibly because the structure of toluene, the solvent chosen for the TD-DFT calculation to approximate the polymer, is similar to a unit of PS but different from a unit of PMMA. In addition, the calculated dipole moment of the damaged species is larger than the pristine DO11 as listed in Table I therefore the damaged species may interact more strongly with PMMA than PS due to the methoxycarbonyl $\left(\mathrm{COOCH}_{3}\right)$ group in PMMA. Nonetheless, the hypsochromic shift in the absorption spectrum and the change in the magnitude of absorbance during photodegradation qualitatively agree with the calculated oscillator strength and the corresponding electronic transition energy for both DO11/PS and DO11/PMMA.

\begin{tabular}{|l|l|l|l|l|l|l|}
\hline Molecules & DO11 & DO11-MMA & DO11-styrene & irr1 & irr2 & irr3 \\
\hline
\end{tabular} \begin{tabular}{|l|c|c|c|c|c|c|}
\hline Dipole moment (D) & 3.07 & 5.84 & 4.37 & 7.77 & 4.69 & 4.55 \\
\hline
\end{tabular}

TABLE I: Dipole moment of DO11 and its photodegraded species obtained using DFT calculation.

\section{A simple model}

An alternative method to verify the above discussion is to calculate the absorbance of reversibly-photodegraded dye species from experimental results by assuming that there is one reversibly-damaged species and effectively one irreversibly-damaged species. In this simple model, it is also assumed that damage to the polymer does not contribute to the UV-Vis absorption spectrum, i.e. it excludes the possibility of any absorption or light scattering due to scattering centers generated from damaged polymer. The calculated absorbance can be regarded as the result of the dominant damage products or the average of several products with similar absorbance.

The absorbance, $A$, measured during decay and recovery at time $t$ can be expressed as

$$
A(t)=n_{0}(t) A_{0}+n_{r}(t) A_{r}+n_{\text {irr }}(t) A_{\text {irr }},
$$

where $n_{0}, n_{r}, n_{i r r}$, and $A_{0}, A_{r}, A_{i r r}$ represent the fraction and the absorbance of the fresh, reversibly-damaged and irreversibly-damaged dye species, respectively. Assuming that dye molecules only convert between three species, $A_{0}$ and $A_{i r r}$ can be experimentally determined from the absorption spectra of a fresh sample and a sample that has been exposed to the pump laser for a long enough time such that the absorption spectrum no longer changes.

The maximum fraction of irreversibly-damaged dye molecules $n_{\text {irr }}(t \rightarrow \infty) \equiv n_{\text {irr }}^{\infty}$ left in a partially recov- 
ered sample can be determined by the absorbance at the time that recovery approaches completion,

$$
\begin{aligned}
A(t \rightarrow \infty) & =n_{0}(t \rightarrow \infty) A_{0}+n_{\text {irr }}(t \rightarrow \infty) A_{\text {irr }} \\
& =A_{0}+n_{\text {irr }}^{\infty}\left(A_{\text {irr }}-A_{0}\right),
\end{aligned}
$$

where we have used the assumption that the presence of only three species yields $n_{0}(t)+n_{r}(t)+n_{\text {irr }}(t)=1$ with $n_{r}(t \rightarrow \infty)=0$. Thus, $n_{i r r}^{\infty}, A_{0}$, and $A_{i r r}$ are obtained experimentally. The absorbance of the reversiblydamaged species $A_{r}$, however, depends on how the three species convert into each other and can be calculated by rewriting Equation 1 at the time, $t_{0}$, that the laser is turned off,

$$
A_{r}=\frac{A\left(t_{0}\right)-n_{0}\left(t_{0}\right) A_{0}-n_{i r r}\left(t_{0}\right) A_{i r r}}{n_{r}\left(t_{0}\right)} .
$$

$n_{\text {irr }}$ is assumed to be a constant after the pump laser is turned off, i.e. $n_{\text {irr }}\left(t \geq t_{0}\right)=n_{i r r}^{\infty}$, which implies that the reversibly-damaged species only recovers back to the fresh dye but does not decay further into the irreversiblydamaged species. With this assumption, $n_{r}\left(t_{0}\right)$ and $n_{i r r}\left(t_{0}\right)$ are proportional to the change in absorbance between $t \rightarrow \infty$ and $t=t_{0}$ and between $t=0$ and $t \rightarrow \infty$, as $n_{r}$ and $n_{\text {irr }}$ shown in Figure 9 and can be used to calculate $A_{r}$ from Equation 3 This assumption can be relaxed to $n_{i r r}\left(t \geq t_{0}\right) \leq n_{i r r}^{\infty}$, in which case the reversibly-damaged species may either decay to the irreversibly-damaged species or recover to the pristine dye, and $n_{r}\left(t_{0}\right)$ and $n_{\text {irr }}\left(t_{0}\right)$ can be numerically adjusted to generate $A_{r}$ using Equation 3 . Note that if this is so, the total fraction of damaged molecules after the laser is turned off at time $t_{0}, n_{r}\left(t \geq t_{0}\right)+n_{\text {irr }}\left(t \geq t_{0}\right)$, is not necessarily the same as in the former case where

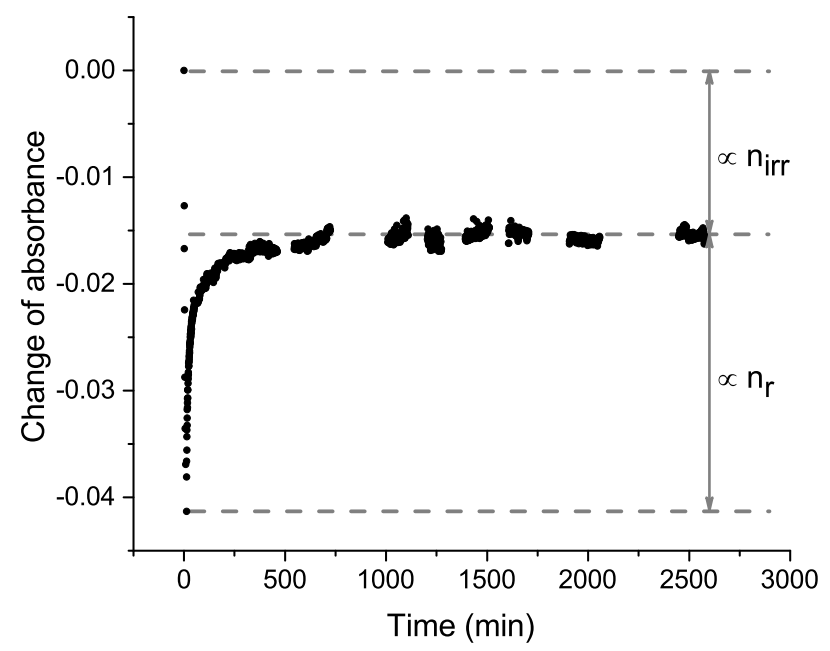

FIG. 9: Change in absorbance of DO11/PMMA during decay and recovery probed at $2.57 \mathrm{eV}(482 \mathrm{~nm})$. The sample was irradiated with a $532 \mathrm{~nm} \mathrm{cw}$ laser for 12 minutes then kept in the dark. irreversibly-damaged species is limited to conversion to the pristine molecule.

In practice, $A_{r}$ and $A_{i r r}$ are determined from two independent experiments, since the reversibly-damaged species recovers but irreversibly-damaged ones don't. The experimental uncertainty thus has contributions from noise from the white light source, the spectrometer and uncertainties due to the determination of the spectra of the two damaged species. However, absorption spectra of the damaged species can be determined qualitatively.

A DO11/PMMA thin film of concentration $9 \mathrm{~g} / \mathrm{L}$ is subjected to long-time photodegradation, and the absorbance of the pristine and irreversibly-damaged sample

(a)
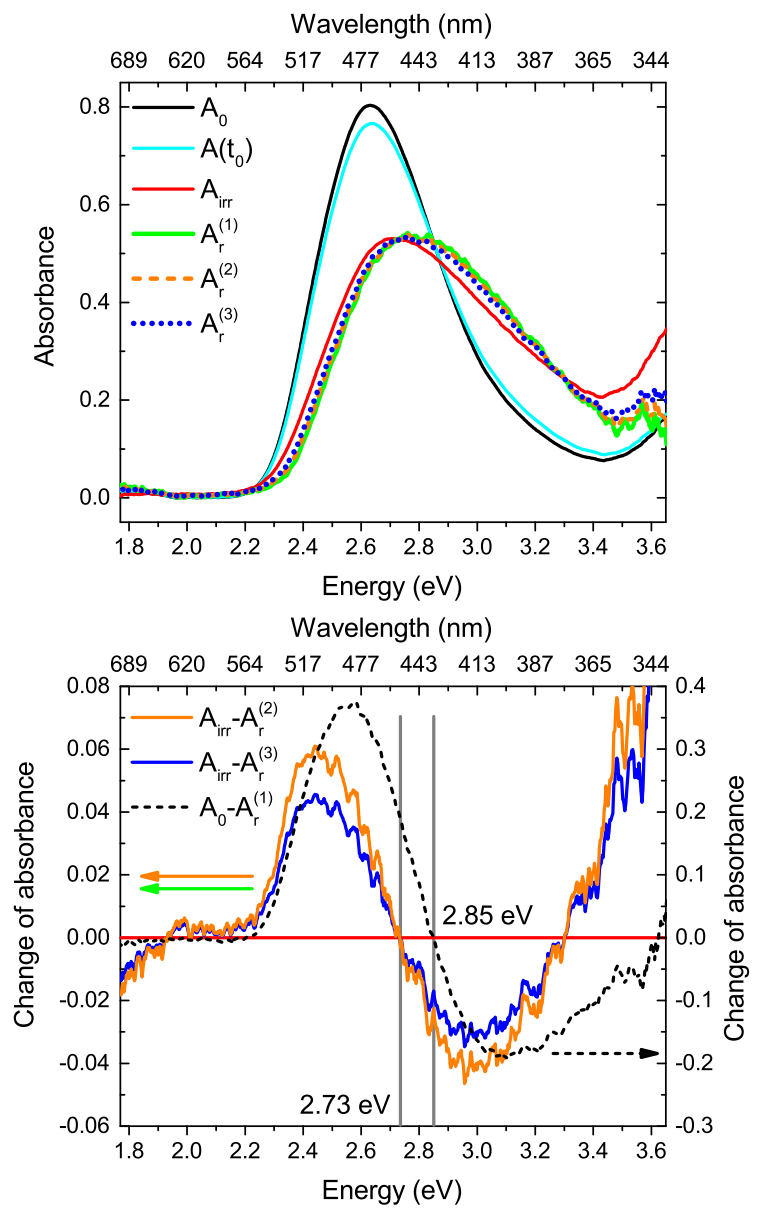

FIG. 10: (a) Absorbance of pristine DO11/PMMA $\left(A_{0}\right)$, reversibly-damaged DO11/PMMA $\left(A_{r}^{(1)}, A_{r}^{(2)}\right.$ and $A_{r}^{(3)}$, depending on the conditions described in the text) and the irreversibly-damaged DO11/PMMA $\left(A_{i r r}\right) . A\left(t_{0}\right)$ is the absorbance of the DO11/PMMA sample measured when the pump laser was turned off. (b) Difference of absorbance between the irreversibly-damaged species and the reversibly-damaged species $\left(A_{r}^{(2)}\right.$ and $A_{r}^{(3)}$, see text and Table (II), and between the pristine dye and the reversibly-damaged species $A_{r}^{(1)}$. 


\begin{tabular}{|l|c|c|c|}
\hline & $n_{0}\left(t_{0}\right)\left(\times 10^{-2}\right)$ & $n_{r}\left(t_{0}\right)\left(\times 10^{-2}\right)$ & $n_{\text {irr }}\left(t_{0}\right)\left(\times 10^{-2}\right)$ \\
\hline \hline$A_{r}^{(1)}$ & $88.26 \pm 0.03$ & $7.35 \pm 0.03$ & $4.40 \pm 0.03\left(n_{\text {irr }}\left(t \geq t_{0}\right)=n_{\text {irr }}^{\infty}\right)$ \\
\hline$A_{r}^{(2)}$ & 88.26 & 8.79 & 2.95 \\
\hline$A_{r}^{(3)}$ & 88.26 & 11.74 & 0 \\
\hline
\end{tabular}

TABLE II: Fractions of the three species $n_{0}, n_{r}$ and $n_{i r r}$ at time $t_{0}$ that result in the corresponding absorbance of the reversibly-damaged DO11/PMMA species $A_{r}^{(1)}, A_{r}^{(2)}$ and $A_{r}^{(3)}$ shown in Figure 10(a).

are shown in Figure 7(a). Another DO11/PMMA sample of the same concentration is characterized during recovery after irradiated by a $532 \mathrm{~nm} \mathrm{cw}$ laser with a peak intensity of $2.09 \mathrm{~W} / \mathrm{cm}^{2}$ for 12 minutes. The absorbance of the pristine DO11/PMMA sample, $A_{0}$, and the absorbance of the DO11/PMMA sample measured at the $12^{\text {th }}$ minute, $A\left(t_{0}\right)$, where $t_{0}=12 \mathrm{~min}$, are shown in Figure 10(a). Since both samples have the same concentration, $A_{i r r}$ of the later sample can be obtained using the Lambert-Beer law and is plotted in Figure10(a). The absorption spectra between 2520 and 2550 minutes were averaged as an approximation of $A(t \rightarrow \infty)$ in Equation 2. and $A(t \rightarrow \infty)$ between $477 \mathrm{~nm}$ and $487 \mathrm{~nm}$ were used to determine the averaged ratio of $n_{1} / n_{2}$. Using Equation 2. $A_{0}$ and $A_{i r r}$ in Figure 10(a), $n_{i r r}$ is determined and also averaged between $477 \mathrm{~nm}$ and $487 \mathrm{~nm}$. Thus, $A_{r}$ is determined using Equation 3 with the assumption that $n_{i r r}\left(t \geq t_{0}\right)$ is constant, as shown in Figure 10(a) by $A_{r}^{(1)}$.

The assumption $n_{\text {irr }}\left(t \geq t_{0}\right)=n_{\text {irr }}^{\infty}$ can be relaxed to $n_{i r r}\left(t_{0}\right) \leq n_{i r r}^{\infty}$ to allow the reversibly-damaged species to either decompose to the irreversibly-damaged species or to recover to the fresh dye. Also assumed is that the total fraction of damaged molecules after time $t_{0}$, $n_{r}\left(t \geq t_{0}\right)+n_{\text {irr }}\left(t \geq t_{0}\right)$, is the same as previously calculated, which may not be true but is used as a guess to study $A_{r}$. Two other values of $n_{i r r}\left(t_{0}\right)$ have been chosen to calculate $A_{r}$, and parameters $n_{0}, n_{r}$ and $n_{i r r}$ at time $t_{0}$ are tabulated in Table $\amalg$ and the calculated absorbance of the reversibly-damaged species, $A_{r}^{(2)}$ and $A_{r}^{(3)}$, are plotted in Figure 10(b). Note that the small uncertainty in Table III results from the analysis done using the peak of changing absorbance (between $477 \mathrm{~nm}$ and $487 \mathrm{~nm}$ ). The purpose of this analysis is to qualitatively determine the absorption spectrum of reversibly-damaged species based on the simple three species model, so the small uncertainty of population does not necessarily mean that the population is accurately determined.

The large difference between the absorbance of the reversibly-damaged species and $A_{i r r}$ observed in the UV regime indicates that the absorbance of reversibly- and irreversibly-damaged dye species is more distinguishable there than in the visible region. However, this statement is based on the assumption that there is only one reversibly- and (effectively) one irreversibly-damaged dye species generated during photodegradation and that the damaged PMMA does not contribute to the absorption spectrum.

The absorbance of the reversibly- and irreversiblydamaged species, $A_{r}^{(1)}$ and $A_{i r r}$, are similar in the visible regime, which is consistent with the results of TD-DFT calculations. The amplitude of the absorbance difference between the fresh molecule, $A_{0}$, and the reversiblydamaged species, $A_{r}^{(1)}$, is approximately 5 times larger than that between the irreversibly-damaged species, $A_{i r r}$, and the reversibly-damaged species, $A_{r}^{(2)}$, and the isosbestic point is found to be at $2.85 \mathrm{eV}$ for recovery and at $2.73 \mathrm{eV}$ for further decay from the reversibly-damaged species as shown in Figure 10(b). The change of absorbance during recovery is plotted with isosbestic points indicated for the spectrum taken at the $12.5^{\text {th }}$ minute and at later times in Figure 11 (recovery starts at the $12^{\text {th }}$ minute). The result indicates that some reversiblydamaged dye species further decay into irreversiblydamaged species after the pump beam is turned off. It also suggests that the further decay of the reversiblydamaged species has a faster rate than the recovery rate since the isosbestic point is observed at $2.75 \mathrm{eV}$ in the beginning of the process (after the pump beam is turned off). However, the isosbestic point quickly shifts to 2.88

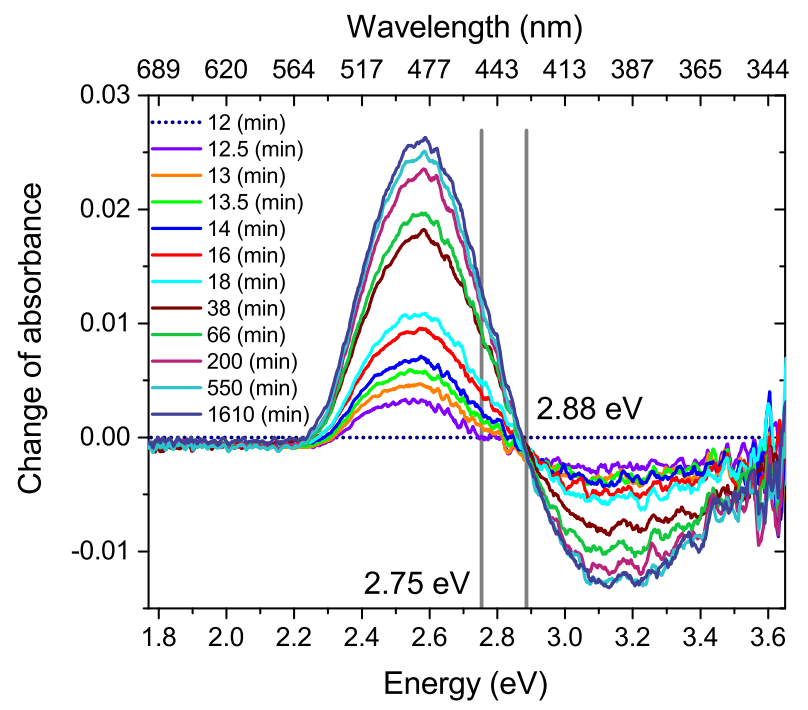

FIG. 11: Change in absorbance of DO11/PMMA thin film relative to the spectrum taken at the $12^{\text {th }}$ minute, the time at which the pump beam is turned off. 
$\mathrm{eV}$ suggesting that the recovery process dominates when the damaged sample is allowed to stay in the dark, which is verified by damaging a DO11/PMMA thin film with a cw laser and probing the recovery using both UV-Vis absorption spectroscopy and amplified spontaneous emission that only comes from pristine DO11 [49].

The absorption spectrum of the reversibly-damaged dye species in DO11/PMMA calculated using the above model qualitatively agrees with the one obtained from TD-DFT calculations. The same agreement is found in DO11/PS thin film samples [49]. Unlike DO11/PMMA, it is concluded that most of the reversibly-damaged dye molecules further decay to the irreversibly-damaged species, which is in agreement with the observed small amount of recovery in a typical DO11/PS sample [49].

\section{FTIR results}

In the PTCR hypothesis, the polymer is involved in the process of photodegradation of dye and may also recover as dye recovers. A UV-Vis absorption spectrum shows peaks due to the dyes in a dye-doped polymer; but since PS and PMMA are transparent in this wavelength range, the contribution from the host polymer is negligible. However, infrared (IR) absorption spectroscopy allows the study of both dye and polymer, so we apply FTIR spectroscopy to monitor the change of chemical bonds in the dye molecules and in the host polymer in reversible photodegradation.

1AAQ/PMMA is chosen for FTIR characterization studies because of the abundant literature on 1AAQ. PS is not studied in the FTIR experiment due to the small degree of recovery, which is difficult to distinguish from noise. A polymerized sample sandwiched between two glass substrates cannot be used in FTIR experiments because glass absorbs IR radiation in the region of interest. So, silicon wafers, which provide a good IR window for this study, are used as substrates for spin-coated films.

A typical polymerized DO11/PMMA sample used in this study has a concentration of $9 \mathrm{~g} / \mathrm{L}$, which corresponds to about $0.32 \%$ number ratio of DO11 in MMA monomer. The same number ratio of $1 \mathrm{AAQ}$ in MMA monomer corresponds to $8.5 \mathrm{~g} / \mathrm{L}$ of $1 \mathrm{AAQ} / \mathrm{PMMA}$ sample. IR absorption from the dye molecules is much weaker than from PMMA at typical dye concentrations. In order to observe possible changes in the IR spectrum from both dye and polymer, the concentration of $1 \mathrm{AAQ} / \mathrm{PMMA}$ is increased to $105 \mathrm{~g} / \mathrm{L}$, about a $3.96 \%$ number ratio of 1AAQ in MMA monomer, resulting in a dye concentration of more than 12 times of a typical polymerized sample.

Even though samples of $1 \mathrm{AAQ} / \mathrm{PMMA}$ are prepared differently, the observed reversible photodegradation in spin-coated samples is the same as in polymerized 1AAQ/PMMA [49]. Though the FTIR experiment is performed in vacuum, and the UV-Vis spectroscopy experiment is open to the air with sandwiched samples between two glass substrates, a test on reversible photodegradation of spin-coated samples suggests that the effect of air is likely negligible during photodegradation and recovery as described in Section A of supplemental material.

The IR spectra of $1 \mathrm{AAQ} / \mathrm{PMMA}$ as a function of time are obtained by subtracting the spectrum of each sample from that of the silicon wafer, and some results of which are shown in Figure 12 together with the IR absorption spectrum of PMMA. The spectrum of $1 \mathrm{AAQ} / \mathrm{PMMA}$ at the $42^{\text {nd }}$ minute is the first spectrum acquired after 30 minutes of irradiation. The spectrum of $1 \mathrm{AAQ} / \mathrm{PMMA}$ at the $1980^{\text {th }}$ minute is the last spectrum taken during recovery.

The $1 \mathrm{AAQ} / \mathrm{PMMA}$ sample needs to be rotated $90^{\circ}$ for laser irradiation and rotated back to its original position to record IR spectra during recovery, which introduces additional variability and is studied by simulating the experiment without irradiating the sample as follows. An IR absorption spectrum of $1 \mathrm{AAQ} / \mathrm{PMMA}$ is obtained by averaging 6000 scans. The sample is then rotated $90^{\circ}$ (without laser irradiation) and rotated back to the original position. Subsequently 1000 scans are averaged to obtain another spectrum and the procedure is repeated. 45 minutes after taking the second spectrum, another spectrum is similarly acquired. The change in the IR absorption spectrum is obtained by subtracting the first spectrum, taken before the sample is rotated, from the later ones. The results of two full cycles of rotation are plotted as "test 1" and "test 2", and the one taken 45 minutes after "test 2" is plotted as "test 3" in Figure 13. The change in first and the last spectra during recovery of a degraded sample relative to the spectrum taken before photodegradation are also plotted in Figure 13 and are found to be distinguishable from noise, except for peaks near $1731 \mathrm{~cm}^{-1}$ due to the nearly saturated absorbance at $1731 \mathrm{~cm}^{-1}$.

The change in IR absorbance of $1 \mathrm{AAQ} / \mathrm{PMMA}$ during recovery relative to the spectrum of the pristine sample is shown in Figure 14(a). IR absorption peaks that change over time are assigned to the corresponding molecular vibration modes as described below and tabulated in Table III. According to Nagai et al., the bands at 1150 and 1194 $\mathrm{cm}^{-1}$ are associated with coupled vibrations of skeletal stretching and internal $\mathrm{C}-\mathrm{H}$ deformation modes, and the band at $1244 \mathrm{~cm}^{-1}$ is associated with the coupled $\mathrm{C}-\mathrm{C}-\mathrm{O}$ and $\mathrm{C}-\mathrm{O}$ stretching vibrations [102, 103]. However, the bands between 1150 and $1300 \mathrm{~cm}^{-1}$ have been attributed later to strong coupling between stretching vibrations of $\mathrm{C}-\mathrm{C}-\mathrm{O}$ and $\mathrm{C}-\mathrm{O}$ or $\mathrm{C}-\mathrm{O}-\mathrm{C}$ and $\mathrm{C}-\mathrm{O}$ of the ester group $\left(\mathrm{R}_{1}-\mathrm{COO}-\mathrm{R}_{2}\right)$ [104 106 . The more current assignment is adopted for the bands at 1150, 1194 and $1244 \mathrm{~cm}^{-1}$ to be coupled $\mathrm{C}-\mathrm{C}-\mathrm{O}-\mathrm{C}$ stretching vibrations. The bending vibrations of $\mathrm{CH}_{2}, \alpha-\mathrm{CH}_{3}$ (in which 


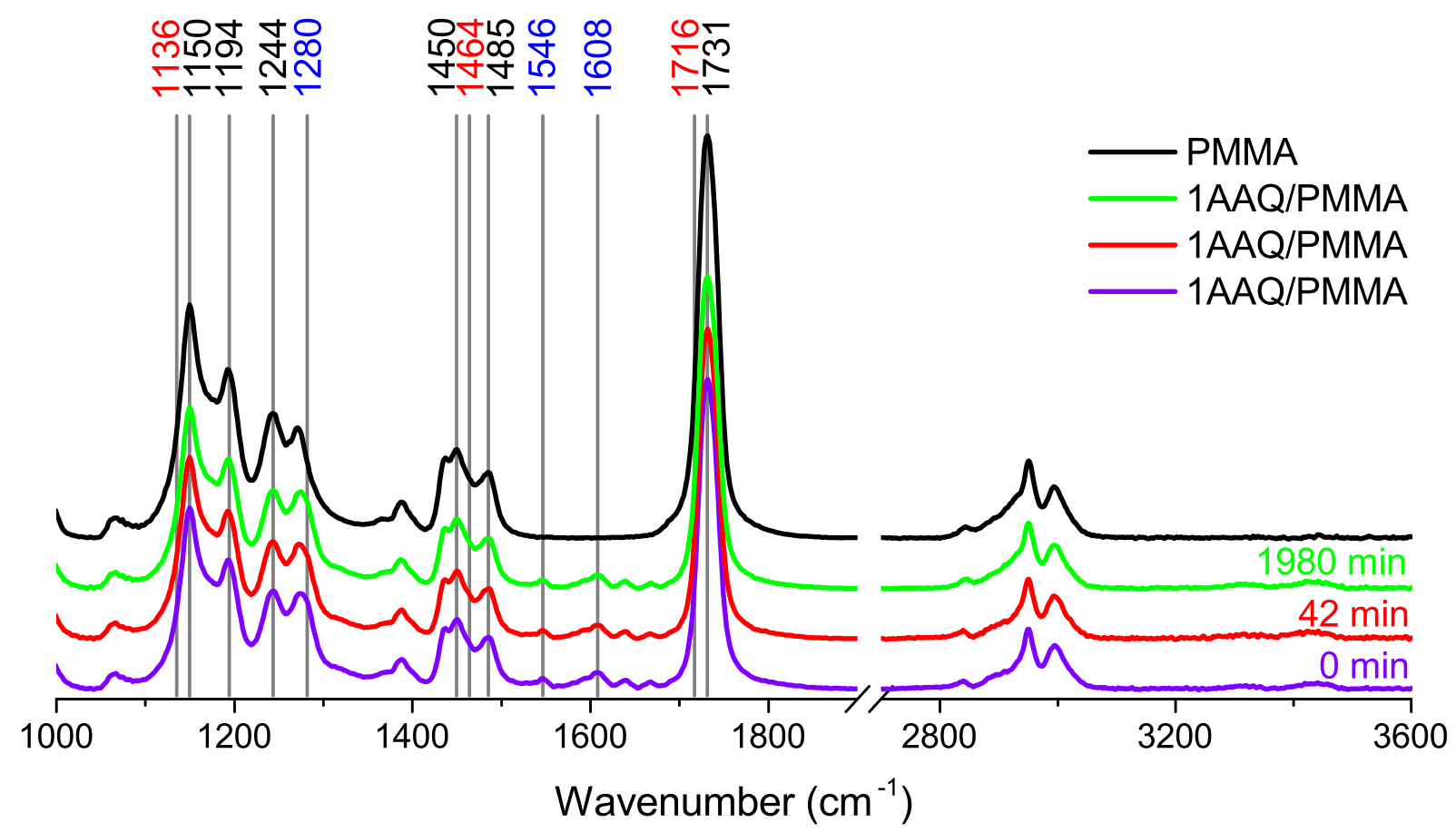

FIG. 12: IR absorbance of PMMA and 1AAQ/PMMA at 0, 42 and 1980 min after the silicon substrate contribution is subtracted. IR absorption peaks that vary during recovery between 1000 and $1800 \mathrm{~cm}^{-1}$ are labeled in black for

PMMA, blue for 1AAQ and red for absorption peaks that do not belong to PMMA and 1AAQ.

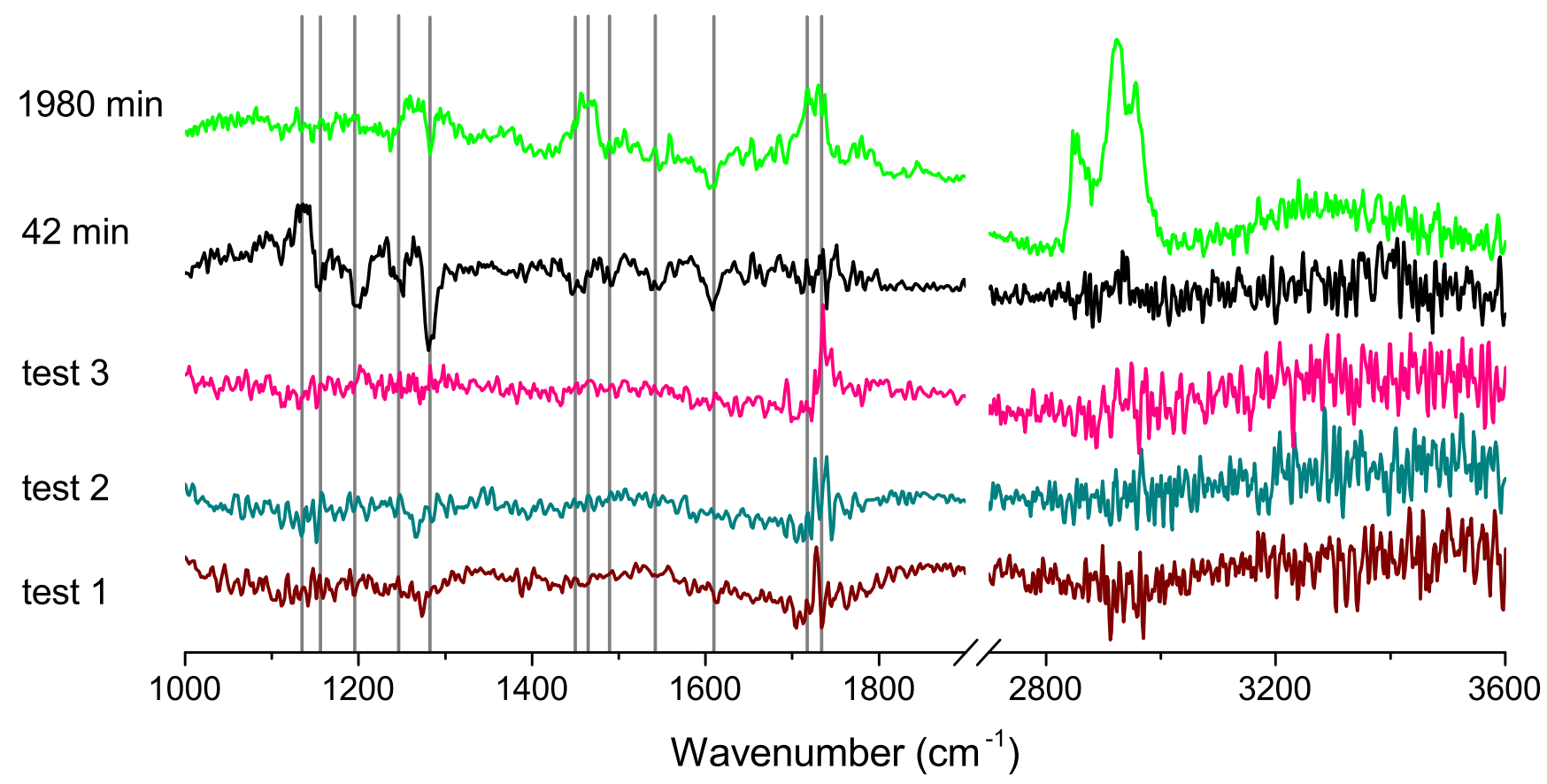

FIG. 13: Comparison of the change in the spectrum of a fresh sample over time (test 1, test 2 and test 3) as a baseline and the change in IR absorbance of 1AAQ/PMMA during recovery at 42 minutes and 1980 minutes. The $42^{\text {nd }}$ minute and $1980^{\text {th }}$ minute are respectively the first spectrum and the last one acquired after 30 minutes irradiation relative to the spectrum of the pristine sample. The vertical lines correspond to the varying IR absorption bands during recovery as assigned in Figure 14 


\begin{tabular}{|c|c|c|}
\hline \begin{tabular}{|l} 
Wavenumber \\
$\left(\mathrm{cm}^{-1}\right)$
\end{tabular} & Molecule & $\begin{array}{l}\text { Corresponding } \\
\text { vibration }\end{array}$ \\
\hline (1150, 1194, 1244 & & $\begin{array}{l}\mathrm{C}-\mathrm{C}-\mathrm{O}-\mathrm{C} \\
\text { stretching }\end{array}$ \\
\hline 1450 & & $\begin{array}{l}\mathrm{CH}_{2}, \alpha-\mathrm{CH}_{3} \text { and } \\
\text { (O) } \mathrm{CH}_{3} \text { bending }\end{array}$ \\
\hline 1485 & & $\begin{array}{c}\alpha-\mathrm{CH}_{3} \text { asymmetric } \\
\text { deformation }\end{array}$ \\
\hline 1731 & & $\mathrm{C}=\mathrm{O}$ stretching \\
\hline 1280 & \multirow{4}{*}{$1 \mathrm{AAQ}$} & $\begin{array}{c}\mathrm{C}-\mathrm{C}-\mathrm{C} \text { stretch of } \\
\text { ketones }\end{array}$ \\
\hline 1546 & & $\begin{array}{l}\text { in-plane } \mathrm{NH}_{2} \\
\text { scissoring }\end{array}$ \\
\hline 1608 & & $\mathrm{C}=\mathrm{O}$ stretching \\
\hline 3320,3440 & & $\mathrm{~N}-\mathrm{H}$ stretching \\
\hline 1136 & & See text \\
\hline \multirow[t]{2}{*}{1464} & & $\mathrm{CH}_{2}$ scissoring \\
\hline & & $\mathrm{C}=\mathrm{O}$ stretching \\
\hline 2850-3000 & & $\mathrm{sp}^{3} \mathrm{CH}$ stretching \\
\hline
\end{tabular}

TABLE III: The assignment of IR absorption bands with each assignment color-coded according to the corresponding molecular structure. The molecular structures shown for molecules other than PMMA and 1AAQ are illustrations of the corresponding IR bands, not necessarily the actual molecules. Details of the assignment of the IR bands are described in the text.

$\alpha$ represents the first carbon atom that is attached to the functional group $\mathrm{COOCH}_{3}$ ) and $(\mathrm{O}) \mathrm{CH}_{3}$ strongly overlap around the band at $1450 \mathrm{~cm}^{-1}[102,103,107]$. The peak at $1485 \mathrm{~cm}^{-1}$ can be assigned to the $\alpha-\mathrm{CH}_{3}$ asymmetric deformation vibration of PMMA 102, 103, 107. While the peak at $1136 \mathrm{~cm}^{-1}$ may be a new peak, it might also be the result of a frequency shift of the $1150 \mathrm{~cm}^{-1}$ peak under irradiation that recovers after the laser is turned off.

The peak at $1280 \mathrm{~cm}^{-1}$ is of the same magnitude as the $1244 \mathrm{~cm}^{-1}$ peak in the IR spectrum of pristine
1AAQ/PMMA in Figure 12 but the $1280 \mathrm{~cm}^{-1}$ is located at the shoulder of the IR absorption peak of PMMA at $1270 \mathrm{~cm}^{-1}$, which is smaller than the $1244 \mathrm{~cm}^{-1}$ peak from pure PMMA, so the peak at $1280 \mathrm{~cm}^{-1}$ is due to $1 \mathrm{AAQ}$ and can be attributed to $\mathrm{C}-\mathrm{C}-\mathrm{C}$ stretch of ketones, i.e. $\mathrm{C}-\mathrm{C}(=\mathrm{O})-\mathrm{C}$ 105. The peak at $1546 \mathrm{~cm}^{-1}$ can be assigned to the in-plane $\mathrm{NH}_{2}$ scissoring of $1 \mathrm{AAQ}$, though is $34 \mathrm{~cm}^{-1}$ lower wavenumbers than the usual frequency range in organic compounds [105], which could be caused by the intramolecular hydrogen bond. The band at 1608 $\mathrm{cm}^{-1}$ can be attributed to the vibration of $\mathrm{C}=\mathrm{O}$ adjacent to the amine group [108 of $1 \mathrm{AAQ}$. It is worth noticing that there is no change in the band at $1667 \mathrm{~cm}^{-1}$, which can be assigned to the vibration of the other $\mathrm{C}=\mathrm{O}$ group of the 1AAQ molecule 108 and is observed in Figure 12 (therefore not labeled in the figure). The symmetric and asymmetric $\mathrm{N}-\mathrm{H}$ stretching modes of the amine group at about $3320 \mathrm{~cm}^{-1}$ and $3440 \mathrm{~cm}^{-1}$ [108] are too noisy to determine whether they changed after irradiation.

Some of the observed changing IR absorption peaks are not due to PMMA and $1 \mathrm{AAQ}$ and originate from changes in the background of the system, such as contamination from pump oil. The peak at $1464 \mathrm{~cm}^{-1}$ is known to be the $\mathrm{CH}_{2}$ scissoring band of hydrocarbons [105, 109]. The band at $1716 \mathrm{~cm}^{-1}$ originates from the $\mathrm{C}=\mathrm{O}$ stretching vibration [105] but not from the aminoanthraquinones, which possess a $\mathrm{C}=\mathrm{O}$ stretch frequency of $1610 \sim 1680$ $\mathrm{cm}^{-1}$ 108, nor from PMMA, which exhibits a $\mathrm{C}=\mathrm{O}$ stretch near $1731 \mathrm{~cm}^{-1}$ 110]. The change of IR absorption bands between 2850 and $3000 \mathrm{~cm}^{-1}$ are known to be the $\mathrm{sp}^{3} \mathrm{CH}$ stretching vibration 105, 109]. These peaks originate from the FTIR system as described in Section B of supplemental material.

In the PTCR hypothesis, it is posited that $1 \mathrm{AAQ}$ undergoes photocycloaddition to MMA that is generated from thermally degraded PMMA to form an oxetane structure - the reversibly-damaged species, or undergoes other (photo)chemical reactions with fragments thermally degraded from PMMA to form the irreversiblydamaged species. Figure 14(b) (f) illustrate the possible damage to $1 \mathrm{AAQ}$ and PMMA and the corresponding change in IR absorption peaks.

The reduction of $\mathrm{C}-\mathrm{C}-\mathrm{O}-\mathrm{C}$ stretching vibrations of PMMA (1150 1300 $\mathrm{cm}^{-1}$ ) after irradiation indicates the scission of the methoxycarbonyl group $\left(\mathrm{COOCH}_{3}\right)$ from PMMA under irradiation. The decrease of $\mathrm{CH}_{2}$ bending $\left(1450 \mathrm{~cm}^{-1}\right)$ and $\alpha-\mathrm{CH}_{3}$ asymmetric deformation $\left(1485 \mathrm{~cm}^{-1}\right)$ of PMMA after irradiation suggests that depolymerization and dissociation of polymer backbones take place under irradiation. Photocycloaddition between $1 \mathrm{AAQ}$ and the depolymerized MMA causes the decrease of the $\mathrm{C}=\mathrm{O}$ vibration peak $\left(1608 \mathrm{~cm}^{-1}\right)$ and the $\mathrm{C}-\mathrm{C}-\mathrm{C}$ stretch peak of ketone $\left(1280 \mathrm{~cm}^{-1}\right)$ in $1 \mathrm{AAQ}$. $1 \mathrm{AAQ}$ and other radicals and fragments dissociated from PMMA can also undergo (photo)chemical reaction to form irreversibly-damaged species and cause the same 

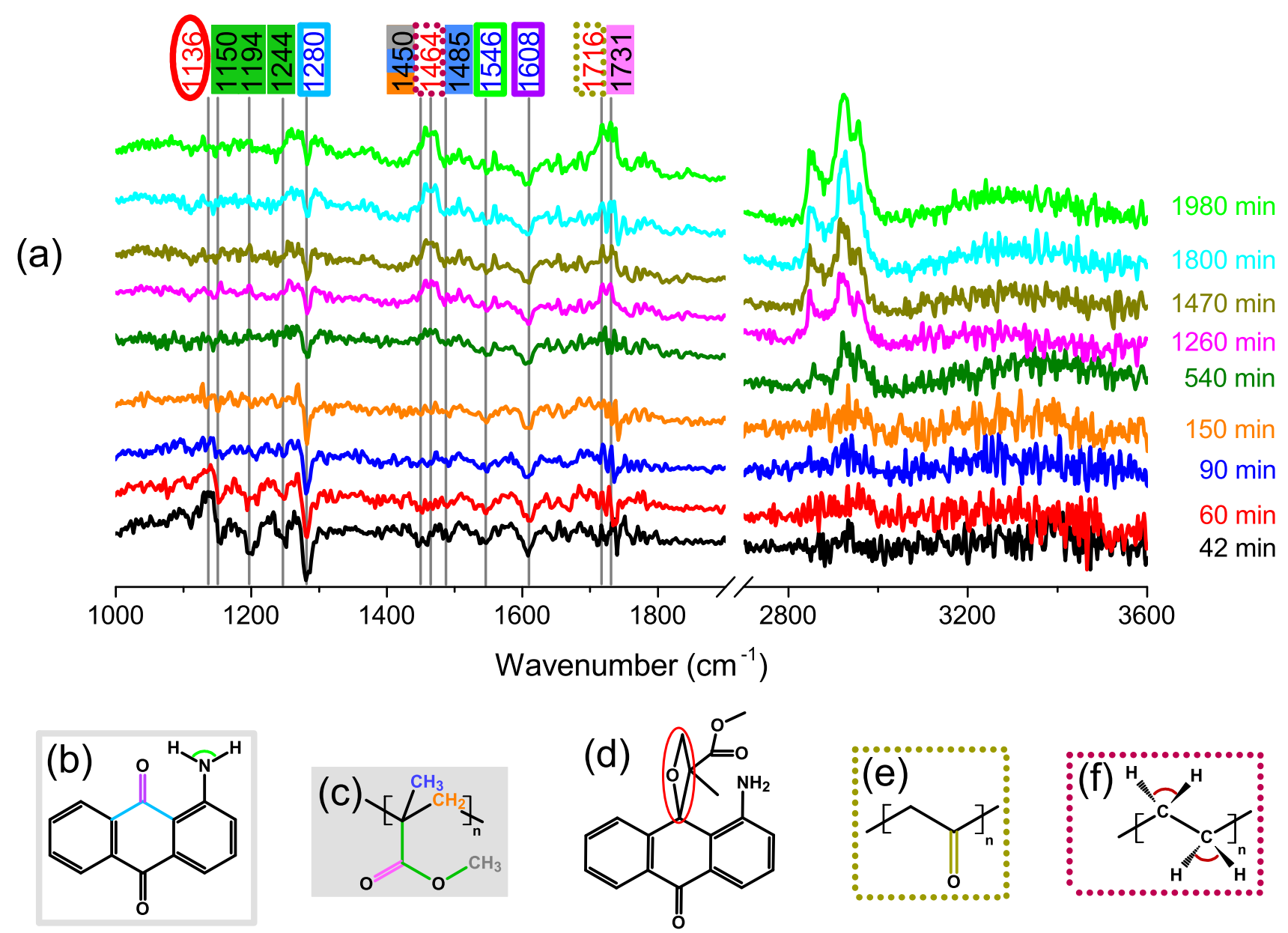

FIG. 14: (a) Evolution of the change in the IR spectrum relative to pristine 1AAQ/PMMA after 30 minutes of irradiation and recovery thereafter. The boxed wavenumbers are color-coded in terms of the bonds indicated in the structures below for (b) 1AAQ shown with hollow solid boxes, (c) PMMA shown with filled boxes, (d) 1AAQ-MMA oxetane shown red circle, (e) and (f) other structures originate from the background of the system shown in dotted boxes.

change in the IR peaks. Note that there is no change from the other $\mathrm{C}=\mathrm{O}$ group of the $1 \mathrm{AAQ}$ molecule at $1667 \mathrm{~cm}^{-1}$ 108, which is consistent with the conclusion obtained from the linear absorption spectroscopy measurements and the TD-DFT calculations in DO11. The reduction in IR peaks of PMMA after irradiation provides evidence of polymer degradation, which supports the PTCR hypothesis.

The in-plane $\mathrm{NH}_{2}$ scissoring of $1 \mathrm{AAQ}$ at $1546 \mathrm{~cm}^{-1}$ may be weakened after irradiation, though the change of the IR peak is noisy. It may be attributed to similar behaviors observed from the ground state geometry optimization of DO11 and its damaged-species in the DFT calculations, i.e. the amine group in the reversibly- and irreversibly-damaged species, though still fairly planar, is observed to become slightly out-of-plane or slightly twisted instead of lying completely in-plane with the skeleton of DO11 as shown in Figure 15.

The IR absorption peaks of oxetane in the gas phase are located at $900 \mathrm{~cm}^{-1}, 995 \mathrm{~cm}^{-1}$, and $2850 \sim 3050 \mathrm{~cm}^{-1}$ 111]. The characteristic IR band of oxetane formed between 1AAQ and olefines was observed at $990 \mathrm{~cm}^{-1}$, and for oxetane formed between $1 \mathrm{AAQ}$ and styrene was found at $970 \mathrm{~cm}^{-1}$ [66. In this study, though, the change in the IR spectrum is relatively noisy in the frequency range below $1000 \mathrm{~cm}^{-1}$ and no significant change is observed between $800 \mathrm{~cm}^{-1}$ and $1000 \mathrm{~cm}^{-1}$ after irradiation. Since the vibration of chemical bonds may be affected by the environment, the growing peak at $1136 \mathrm{~cm}^{-1}$ after irradiation may be attributed to oxetane formed between 1AAQ and MMA as shown in Figure 14(d). The recovery of the peak at $1136 \mathrm{~cm}^{-1}$ indicates that $1 \mathrm{AAQ}$ MMA oxetane molecules return to $1 \mathrm{AAQ}$ and MMA or further decay into irreversibly-damaged species. Alternatively, the peak at $1136 \mathrm{~cm}^{-1}$ may result from a frequency 


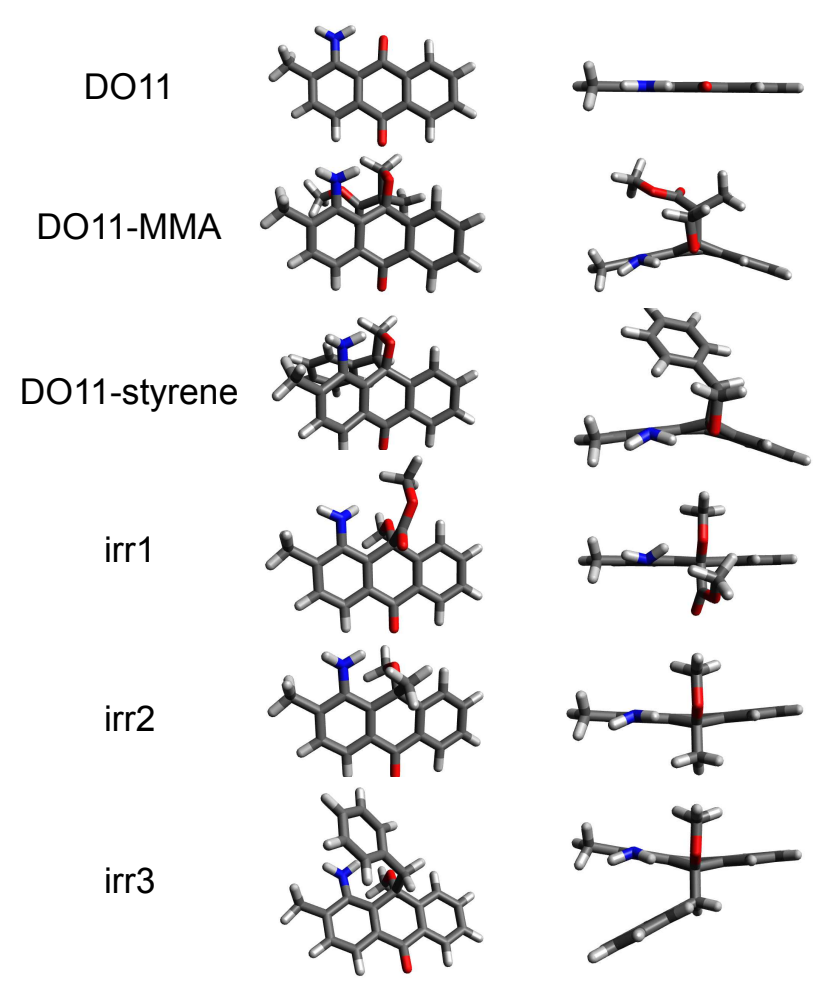

FIG. 15: Molecular structures of DO11 and possible damaged species. Colors in molecular structures have the same meaning as in Figure 8 .

shift of the $1150 \mathrm{~cm}^{-1}$ peak due to the dissociation of the $\mathrm{COOCH}_{3}$ group from PMMA under irradiation and recovers after the laser is turned off. In this case, another photochemical reaction other than photocycloaddition between $1 \mathrm{AAQ}$ and MMA may occur resulting in a reversibly-damaged dye species since the vibration frequency of oxetane is not observed. Nonetheless, the reversible damage of $1 \mathrm{AAQ}$ occurring at the carbonyl group adjacent to the amine group is observed.

The change in the IR absorption peak at $1280 \mathrm{~cm}^{-1}$, which corresponds to the $\mathrm{C}-\mathrm{C}-\mathrm{C}$ stretching vibration of ketone adjacent to the amine group in $1 \mathrm{AAQ}$, partially recovers and is distinguishable until the $540^{\text {th }}$ minute. However, a growing peak at $1280 \mathrm{~cm}^{-1}$ is also observed at long-times as described in Section B of supplemental material. Thus, the recovery of the peak at $1280 \mathrm{~cm}^{-1}$ may have become indistinguishable from noise at the $150^{\text {th }}$ minute. It is difficult to determine the time that the recovery of the in-plane $\mathrm{NH}_{2}$ scissoring band at $1546 \mathrm{~cm}^{-1}$ and the carbonyl group stretching band at $1608 \mathrm{~cm}^{-1}$ becomes indistinguishable from noise due to the small signal-to-noise $(\mathrm{S} / \mathrm{N})$ ratio of the spectrum. While partial recovery of $1 \mathrm{AAQ}$ agrees with the observation in absorption spectroscopy measurements, the reduced IR peaks belonging to PMMA fully recover at the $150^{\text {th }}$ minute. The disagreement of recovery dynamics between $1 \mathrm{AAQ}$ and PMMA may originate from the changes in the background of the system due to contamination as described in Section B of supplemental material, the small S/N ratio of the spectrum, and uncertainties and artifacts that arise from the baseline process used for obtaining the spectra. Nonetheless, the experimental results qualitatively agree with the PTCR hypothesis.

The PTCR hypothesis is consistent with the spectra predicted using TD-DFT calculations, the measured absorption spectra of the pristine and irreversibly-damaged species, the absorption spectrum of the reversiblydamaged species obtained using a simple three species model, and changes in molecular structures of dye and polymer upon photodegradation and during recovery observed in the FTIR experiment in this study. The chemical reactions involved in the PTCR hypothesis suggest that the decay and recovery processes may be governed by energy barriers among pristine dye and degraded dye species. However, the energy barrier scenario seems to contradict a phenomenological model that is based on quantitative studies of reversible photodegradation in DO11/PMMA using various experimental techniques 51, 52, 54]. The kinetics of the decay and recovery processes are currently under investigation to better understand the possible causes of the disagreement as briefly discussed elsewhere [49].

\section{CONCLUSION}

The mechanism responsible for reversible photodegradation in 1-substitued aminoanthraquinone-doped polymers has been studied using GPC, TD-DFT calculatioins, UV-Vis and FTIR spectroscopy. GPC experiments eliminate the possibility of residual monomers being responsible for the observed reversible photodegradation in dye-doped polymers. TD-DFT calculations indicate that the reversible and irreversible degradation in the dye molecule occur at the carbonyl group adjacent to the amine group, and qualitatively agrees with the experimental results obtained using UV-Vis and FTIR spectroscopy. Studies using FTIR spectroscopy also indicates that both dye and polymer undergo reversible photodegradation, instead of the dye alone. These results suggest that photodegradation is caused by (photo)chemical reactions between pristine dye and the photoinduced thermally-degraded polymer, and recovery is due to the metastable (photo)chemical reaction product returning back to pristine dye.

The observed photoinduced thermal degradation may occur in various doped polymers, and thus (photo)chemical reactions between dopants and thermally-degraded polymers may be one common mechanism responsible for reversible and irreversible photodegradation depending on the stability of the reaction products. Thus, photoinduced thermal degradation 
in polymers is a factor that should be taken into account, in addition to the effects of oxygen, moisture etc., to understand how to improve the stability of doped polymer materials when light exposure is required. Methods such as reducing the probability of non-radiative relaxation from dopants, increasing the thermal degradation temperature of the polymer host, increasing the heat dissipation rate of polymer chains, selecting proper dopants that do not react with thermally degraded polymers under the operating condition (if local thermal degradation of polymer chains is not a concern) etc. are possible approaches to improve photostability.

Although energy transfer between dye and polymer is the key to photodegradation, the mechanism of the energy transfer is not clear. Understanding the mechanism of energy transfer between dye and polymer will provide a new perspective to design desirable dye-doped polymer materials. For example, Förster resonance energy transfer theory has been applied to simulate the dynamics of dye excitation and energy transfer in nanostructured DNA-dye assemblies for light-harvesting applications [112]. The study in kinetics of reversible photodegradation of dye-doped polymers is currently ongoing. The available results so far suggest that the local environment of dye molecules drastically affects the photodegradation and recovery rate [49], hence the energy transfer between dye and polymer and the involved (photo)chemical reactions may greatly depend on the distribution of dye in the polymer host. The knowledge of energy transfer mechanism and dye distribution in the polymer can be applied to design dye-doped polymers with improved device performance and photostability.

\section{ACKNOWLEDGMENTS}

S.T.H. and M.G.K. thank Prof. Kirk A. Peterson for valuable help and advice in TD-DFT calculations, and Wright-Patterson Air Force Base and Air Force Office of Scientific Research (FA9550- 10- 1-0286) for their support of this research. S.T.H. thanks Dr. Candy C. Mercado for valuable discussion in molecular spectroscopy, and WSU for a College of Arts and Sciences Research Assistantship.

\section{* sth@wsu.edu}

[1] J. G. White, W. B. Amos, and M. Fordham, "An evaluation of confocal versus conventional imaging of biological structures by fluorescence light microscopy," The Journal of Cell Biology 105, 41-48 (1987).

[2] W. Denk, J. H. Strickler, and W. W. Webb, "Twophoton laser scanning fluorescence microscopy," Science 248, 73-76 (1990).
[3] W. R. Zipfel, R. M. Williams, and W. W. Webb, "Nonlinear magic: multiphoton microscopy in the biosciences," Nature biotechnology 21, 1369-1377 (2003).

[4] B. Huang, M. Bates, and X. Zhuang, "Super resolution fluorescence microscopy," Annual review of biochemistry 78, 993-1016 (2009).

[5] E. H. Rego, L. Shao, J. J. Macklin, L. Winoto, G. A. Johansson, N. Kamps-Hughes, M. W. Davidson, and M. G. Gustafsson, "Nonlinear structured-illumination microscopy with a photoswitchable protein reveals cellular structures at 50-nm resolution," Proceedings of the National Academy of Sciences 109, E135-E143 (2012).

[6] S. van de Linde, M. Heilemann, and M. Sauer, "Live-cell super-resolution imaging with synthetic fluorophores," Annual review of physical chemistry 63, 519-540 (2012).

[7] N. G. Horton, K. Wang, D. Kobat, C. G. Clark, F. W. Wise, C. B. Schaffer, and C. Xu, "In vivo three-photon microscopy of subcortical structures within an intact mouse brain," Nature photonics 7, 205-209 (2013).

[8] J. E. Reeve, H. A. Collins, K. D. Mey, M. M. Kohl, K. J. Thorley, O. Paulsen, K. Clays, and H. L. Anderson, "Amphiphilic porphyrins for second harmonic generation imaging," Journal of the American Chemical Society 131, 2758-2759 (2009). PMID: 19209855.

[9] J. E. Reeve, H. L. Anderson, and K. Clays, "Dyes for biological second harmonic generation imaging," Phys. Chem. Chem. Phys. 12, 13484-13498 (2010).

[10] E. De Meulenaere, W.-Q. Chen, S. Van Cleuvenbergen, M.-L. Zheng, S. Psilodimitrakopoulos, R. Paesen, J.M. Taymans, M. Ameloot, J. Vanderleyden, P. LozaAlvarez, X.-M. Duan, and K. Clays, "Molecular engineering of chromophores for combined second-harmonic and two-photon fluorescence in cellular imaging," Chem. Sci. 3, 984-995 (2012).

[11] I. Lopez-Duarte, J. E. Reeve, J. Perez-Moreno, I. Boczarow, G. Depotter, J. Fleischhauer, K. Clays, and H. L. Anderson, " "push-no-pull" porphyrins for second harmonic generation imaging," Chem. Sci. 4, 20242027 (2013).

[12] S. Redon, J. Massin, S. Pouvreau, E. De Meulenaere, K. Clays, Y. Queneau, C. Andraud, A. Girard-Egrot, Y. Bretonnière, and S. Chambert, "Red emitting neutral fluorescent glycoconjugates for membrane optical imaging," Bioconjugate Chemistry 25, 773-787 (2014). PMID: 24528385.

[13] H. Hoppe and N. S. Sariciftci, "Organic solar cells: An overview," Journal of Materials Research 19, 1924-1945 (2004).

[14] S. Günes, H. Neugebauer, and N. S. Sariciftci, "Conjugated polymer-based organic solar cells," Chemical Reviews 107, 1324-1338 (2007). PMID: 17428026.

[15] A. Hagfeldt, G. Boschloo, L. Sun, L. Kloo, and H. Pettersson, "Dye-sensitized solar cells," Chemical Reviews 110, 6595-6663 (2010). PMID: 20831177.

[16] G. Li, R. Zhu, and Y. Yang, "Polymer solar cells," Nature Photonics 6, 153-161 (2012).

[17] D. N. Congreve, J. Lee, N. J. Thompson, E. Hontz, S. R. Yost, P. D. Reusswig, M. E. Bahlke, S. Reineke, T. Van Voorhis, and M. A. Baldo, "External quantum efficiency above $100 \%$ in a singlet-exciton-fission-based organic photovoltaic cell," Science 340, 334-337 (2013).

[18] A. Costela, I. Garcia-Moreno, and R. Sastre, "Polymeric solid-state dye lasers: Recent developments," Phys. Chem. Chem. Phys. 5, 4745-4763 (2003). 
[19] S. Chénais and S. Forget, "Recent advances in solidstate organic lasers," Polymer International 61, 390-406 (2012).

[20] V. W. Chen, N. Sobeshchuk, C. Lafargue, E. S. Mansfield, J. Yom, L. R. Johnstone, J. M. Hales, S. Bittner, S. Charpignon, D. Ulbricht, J. Lautru, I. Denisyuk, J. Zyss, J. W. Perry, and M. Lebental, "Three-dimensional organic microlasers with low lasing thresholds fabricated by multiphoton and UV lithography," Opt. Express 22, 12316-12326 (2014).

[21] A. P. Kulkarni, C. J. Tonzola, A. Babel, and S. A. Jenekhe, "Electron transport materials for organic lightemitting diodes," Chemistry of Materials 16, 4556-4573 (2004).

[22] K. T. Kamtekar, A. P. Monkman, and M. R. Bryce, "Recent advances in white organic light-emitting materials and devices (WOLEDs)," Advanced Materials 22, 572-582 (2010).

[23] S. Santra, J. Xu, K. Wang, and W. Tand, "Luminescent nanoparticle probes for bioimaging," Journal of Nanoscience and Nanotechnology 4, 590-599 (2004).

[24] G. Donnert, J. Keller, R. Medda, M. A. Andrei, S. O. Rizzoli, R. Lührmann, R. Jahn, C. Eggeling, and S. W. Hell, "Macromolecular-scale resolution in biological fluorescence microscopy," Proceedings of the National Academy of Sciences 103, 11440-11445 (2006).

[25] R. Hoebe, C. Van Oven, T. W. Gadella, P. Dhonukshe, C. Van Noorden, and E. Manders, "Controlled light-exposure microscopy reduces photobleaching and phototoxicity in fluorescence live-cell imaging," Nature biotechnology 25, 249-253 (2007).

[26] H. G. Agrell, J. Lindgren, and A. Hagfeldt, "Degradation mechanisms in a dye-sensitized solar cell studied by UV-VIS and IR spectroscopy," Solar Energy 75, 169180 (2003).

[27] M. Ahmad, T. A. King, D.-K. Ko, B. H. Cha, and J. Lee, "Performance and photostability of xanthene and pyrromethene laser dyes in sol-gel phases," Journal of Physics D: Applied Physics 35, 1473-1476 (2002).

[28] M. Jørgensen, K. Norrman, S. A. Gevorgyan, T. Tromholt, B. Andreasen, and F. C. Krebs, "Stability of polymer solar cells," Advanced Materials 24, 580-612 (2012).

[29] A. Tournebize, P.-O. Bussière, A. Rivaton, J.-L. Gardette, H. Medlej, R. C. Hiorns, C. Dagron-Lartigau, F. C. Krebs, and K. Norrman, "New insights into the mechanisms of photodegradation/stabilization of P3HT:PCBM active layers using poly(3-hexyl-d13thiophene)," Chemistry of Materials 25, 4522-4528 (2013).

[30] H. Cao, W. He, Y. Mao, X. Lin, K. Ishikawa, J. H. Dickerson, and W. P. Hess, "Recent progress in degradation and stabilization of organic solar cells," Journal of Power Sources 264, 168 - 183 (2014).

[31] G. D. Peng, Z. Xiong, and P. L. Chu, "Fluorescence decay and recovery in organic dye-doped polymer optical fibers," J. Lightwave Technol. 16, 2365 (1998).

[32] O. V. Przhonska, J. H. Lim, D. J. Hagan, E. W. V. Stryland, M. V. Bondar, and Y. L. Slominsky, "Nonlinear light absorption of polymethine dyes in liquid and solid media," J. Opt. Soc. Am. B 15, 802-809 (1998).

[33] B. F. Howell and M. G. Kuzyk, "Amplified spontaneous emission and recoverable photodegradation in polymer doped with disperse orange 11," J. Opt. Soc. Am. B 19,
1790 - 1793 (2002).

[34] P. K. Singh and S. T. Lakshmikumar, "Quenching and recovery of photoluminescence intensity of silicon nanoparticles embedded in optically transparent polymers," Semiconductor Science and Technology 17, 1123 (2002).

[35] P. Kobrin, R. Fisher, and A. Gurrola, "Reversible photodegradation of organic light-emitting diodes," Applied Physics Letters 85, 2385-2387 (2004).

[36] M. Biancardo, K. West, and F. C. Krebs, "Optimizations of large area quasi-solid-state dye-sensitized solar cells," Solar Energy Materials and Solar Cells 90, 25752588 (2006).

[37] E. A. Katz, S. Gevorgyan, M. S. Orynbayev, and F. C. Krebs, "Out-door testing and long-term stability of plastic solar cells," The European Physical Journal - Applied Physics 36, 307-311 (2006).

[38] Y. Zhu, J. Zhou, and M. G. Kuzyk, "Two-photon fluorescence measurements of reversible photodegradation in a dye-doped polymer," Opt. Lett. 32, 958-960 (2007).

[39] L. DesAutels, M. G. Kuzyk, and C. Brewer, "Femtosecond bulk transparent material processing and recovery," Opt. Express 17, 18808 - 18819 (2009).

[40] A. Seemann, H.-J. Egelhaaf, C. J. Brabec, and J. A. Hauch, "Influence of oxygen on semi-transparent organic solar cells with gas permeable electrodes," Organic Electronics 10, 1424 - 1428 (2009).

[41] B. Anderson, S. Ramini, and M. Kuzyk, "Imaging studies of photodamage and self-healing of anthraquinone derivative dye doped polymers," SPIE Laser Damage Symposium Proc. 8190-16, 81900N (2011).

[42] B. R. Anderson, "Testing a generalized domain model of photodegradation and self-healing using novel optical characterization techniques and the effects of an applied electric field," Ph.D. thesis, WASHINGTON STATE UNIVERSITY (2013).

[43] I. Ayesta, M. Illarramendi, J. Arrue, F. Jimenez, and J. Zubia, "Two-photon-excited emission in polymer optical fibers doped with a conjugated polymer," Photonics Journal, IEEE 6, 1-9 (2014).

[44] B. R. Anderson, R. Gunawidjaja, and H. Eilers, "Selfhealing organic-dye-based random lasers," Opt. Lett. 40, 577-580 (2015).

[45] S.-T. Hung, S. K. Ramini, D. G. Wyrick, K. Clays, and M. G. Kuzyk, "The role of the polymer host on reversible photodegradation in disperse orange 11 dye," Proc. SPIE 8474, 84741A (2012).

[46] N. B. Embaye, S. K. Ramini, and M. G. Kuzyk, "Mechanisms of reversible photodegradation in disperse orange 11 dye doped in PMMA polymer," The Journal of Chemical Physics 129, 054504 (2008).

[47] S. K. Ramini, N. Dawson, and M. G. Kuzyk, "Testing the diffusion hypothesis as a mechanism of self-healing in disperse orange 11 doped in poly(methyl methacrylate)," J. Opt. Soc. Am. B 28, 2408-2412 (2011).

[48] B. Anderson, S. K. Ramini, and M. G. Kuzyk, "Imaging studies of photodamage and self-healing in disperse orange 11 dye-doped PMMA," J. Opt. Soc. Am. B 28, 528-532 (2011).

[49] S.-T. Hung, "Spectroscopic investigations of inhomogeneous barrier mechanisms of reversible photodegradation of aminoanthraquinone-doped polymer matrices," Ph.D. thesis, Washington State University and Katholieke Universiteit Leuven (2015). 
[50] S. K. Ramini, "Experimental investigations of a proposed chromophore correlation model of self healing of disperse orange 11 doped in poly(methyl methacrylate)," Ph.D. thesis, Washington State University (2012).

[51] S. K. Ramini and M. G. Kuzyk, "A self healing model based on polymer-mediated chromophore correlations," The Journal of Chemical Physics 137, 054705 (2012).

[52] S. K. Ramini, B. Anderson, S.-T. Hung, and M. G. Kuzyk, "Experimental tests of a new correlated chromophore domain model of self-healing in a dye-doped polymer," Polym. Chem. 4, 4948-4954 (2013).

[53] B. Anderson, S.-T. Hung, and M. G. Kuzyk, "Influence of an electric field on photodegradation and self-healing in disperse orange 11 dye-doped PMMA thin films," J. Opt. Soc. Am. B 30, 3193 - 3201 (2013).

[54] B. Anderson and M. G. Kuzyk, "Generalizing the correlated chromophore domain model of reversible photodegradation to include the effects of an applied electric field," Physical Review E 89, 032601 (2014).

[55] N. J. Westfall and C. W. Dirk, "The photochemistry of the self-healing chromophore disperse orange 11," Journal of Physical Organic Chemistry 25, $704-712$ (2012).

[56] M. G. Kuzyk and S. Ramini, "Correlated aggregate model of self-healing in dye-doped polymers," Proc. SPIE 8519, 85190E (2012).

[57] M. G. Kuzyk and S. Ramini, "The role of polymermediated dopant correlations in damage moderation and self healing," Proc. SPIE 8530, 853014 (2012).

[58] M. Hocking and S. Mattar, "Electron paramagnetic resonance examination of aqueous anthrasemiquinone radical anion," Journal of Magnetic Resonance (1969) 47, $187-199$ (1982).

[59] S. van de Linde, I. Krstic, T. Prisner, S. Doose, M. Heilemann, and M. Sauer, "Photoinduced formation of reversible dye radicals and their impact on superresolution imaging," Photochem. Photobiol. Sci. 10, 499-506 (2011).

[60] P. F. Gordon and P. Gregory, Organic chemistry in colour (Springer-Verlag, 1983). Chapter 4.

[61] D. Zarzeczańska, P. Niedziałkowski, A. Wcisło, L. Chomicz, J. Rak, and T. Ossowski, "Synthesis, redox properties, and basicity of substituted 1aminoanthraquinones: spectroscopic, electrochemical, and computational studies in acetonitrile solutions," Structural Chemistry 25, 625-634 (2014).

[62] J. M. Bruce, The chemistry of the quinonoid compounds, Part I (John Wiley \& Sons, 1974). Chapter 9.

[63] H. Inoue, T. Hoshi, J. Yoshino, and Y. Tanizaki, "The polarized absorption spectra of some $\alpha$ aminoanthraquinones," Bulletin of the Chemical Society of Japan 45, 1018-1021 (1972).

[64] H. Inoue, T. Hoshi, J. Yoshino, and Y. Tanizaki, "The polarized absorption spectra of some $\beta$-substituted anthraquinones," Bulletin of the Chemical Society of Japan 46, 380-384 (1973).

[65] H. Inoue, A. Ezaki, H. Tomono, and M. Hida, "Photocycloaddition of 1-aminoanthraquinones to dienes by visible light irradiation," J. Chem. Soc., Chem. Commun. pp. 860-861 (1979).

[66] H. Inoue, A. Ezaki, D. Nakajima, H. Tomono, and M. Hida, "Photocycloaddition of 1aminoanthraquinones to dienes by visible light irradiation," J. Chem. Soc., Perkin Trans. 1 pp.
1771-1773 (1982)

[67] H. Inoue, A. Ezaki, and M. Hida, "Mechanism of the photocycloaddition of 1-aminoanthraquinones to olefins by visible light irradiation; oxetan formation via an exciplex," J. Chem. Soc., Perkin Trans. 2 pp. 833-839 (1982).

[68] N. Grassie and G. Scott, Polymer degradation and stabilisation (Cambridge University Press, 1985).

[69] I. McNeill, M. Zulfiqar, and T. Kousar, "A detailed investigation of the products of the thermal degradation of polystyrene," Polymer Degradation and Stability 28 , $131-151$ (1990).

[70] L. E. Manring, "Thermal degradation of poly(methyl methacrylate). 4. random side-group scission," Macromolecules 24, 3304-3309 (1991).

[71] J. D. Peterson, S. Vyazovkin, and C. A. Wight, "Kinetics of the thermal and thermo-oxidative degradation of polystyrene, polyethylene and poly (propylene)," Macromolecular Chemistry And Physics 202, 775-784 (2001).

[72] M. Ferriol, A. Gentilhomme, M. Cochez, N. Oget, and J. Mieloszynski, "Thermal degradation of poly (methyl methacrylate) (PMMA): modelling of DTG and TG curves," Polymer Degradation and Stability 79, 271 281 (2003).

[73] S. I. Stoliarov, P. R. Westmoreland, M. R. Nyden, and G. P. Forney, "A reactive molecular dynamics model of thermal decomposition in polymers: I. poly(methyl methacrylate)," Polymer 44, 883 - 894 (2003).

[74] L. E. Manring, "Thermal degradation of saturated poly(methyl methacrylate)," Macromolecules 21, 528530 (1988).

[75] L. E. Manring, "Thermal degradation of poly(methyl methacrylate). 2. vinyl-terminated polymer," Macromolecules 22, 2673-2677 (1989).

[76] L. E. Manring, D. Y. Sogah, and G. M. Cohen, "Thermal degradation of poly(methyl methacrylate). 3. polymer with head-to-head linkages," Macromolecules 22, 46524654 (1989).

[77] T. Kashiwagi, T. Hirata, and J. E. Brown, "Thermal and oxidative degradation of poly(methyl methacrylate) molecular weight," Macromolecules 18, 131-138 (1985).

[78] T. Kashiwagi, A. Inaba, J. E. Brown, K. Hatada, T. Kitayama, and E. Masuda, "Effects of weak linkages on the thermal and oxidative degradation of poly(methyl methacrylates)," Macromolecules 19, 2160-2168 (1986).

[79] T. Hirata, T. Kashiwagi, and J. E. Brown, "Thermal and oxidative degradation of poly(methyl methacrylate): weight loss," Macromolecules 18, 1410-1418 (1985).

[80] B. Holland and J. Hay, "The kinetics and mechanisms of the thermal degradation of poly(methyl methacrylate) studied by thermal analysis-fourier transform infrared spectroscopy," Polymer 42, 4825 - 4835 (2001).

[81] B. Holland and J. Hay, "The effect of polymerisation conditions on the kinetics and mechanisms of thermal degradation of PMMA," Polymer Degradation and Stability 77, $435-439$ (2002).

[82] Y.-H. Hu and C.-Y. Chen, "The effect of end groups on the thermal degradation of poly(methyl methacrylate)," Polymer Degradation and Stability 82, 81-88 (2003).

[83] H. Inoue, M. Hida, N. Nakashima, and K. Yoshihara, "Picosecond fluorescence lifetimes of anthraquinone derivatives. radiationless deactivation via intra- and intermolecular hydrogen bonds," The Journal of Physical 
Chemistry 86, 3184-3188 (1982).

[84] P. Dahiya, M. Kumbhakar, D. Maity, T. Mukherjee, A. Tripathi, N. Chattopadhyay, and H. Pal, "Solvent polarity and intramolecular hydrogen bonding effects on the photophysical properties of 1-amino-9,10anthraquinone dye," Journal of Photochemistry and Photobiology A: Chemistry 181, 338 - 347 (2006).

[85] J. F. Rabek and B. Rånby, "Studies on the photooxidation mechanism of polymers. ii. the role of quinones as sensitizers in the photooxidative degradation of polystyrene," Journal of Polymer Science: Polymer Chemistry Edition 12, 295-306 (1974).

[86] I. Mita, T. Takagi, K. Horie, and Y. Shindo, "Photosensitized degradation of polystyrene by benzophenone in benzene solution," Macromolecules 17, 2256-2260 (1984).

[87] I. Mita, T. Hisano, K. Horie, and A. Okamoto, "Photoinitiated thermal degradation of polymers. i. elementary processes of degradation of polystyrene," Macromolecules 21, 3003-3010 (1988).

[88] H. Kaczmarek, A. Kamińska, M. Światek, and S. Sanyal, "Photoinitiated degradation of polystyrene in the presence of low-molecular organic compounds," European Polymer Journal 36, 1167 - 1173 (2000).

[89] I. Mita, K. Obata, and K. Horie, "Photoinitiated thermal degradation of polymers ii. poly (methyl methacrylate)," Polymer Journal 22, 397-410 (1990).

[90] O. Chiantore, L. Trossarelli, and M. Lazzari, "Photooxidative degradation of acrylic and methacrylic polymers," Polymer 41, 1657 - 1668 (2000).

[91] H. Fukumura, N. Mibuka, S. Eura, and H. Masuhara, "Mass spectrometric studies on laser ablation of polystyrene sensitized with anthracene," The Journal of Physical Chemistry 97, 13761-13766 (1993).

[92] C. Egami, Y. Kawata, Y. Aoshima, H. Takeyama, F. Iwata, O. Sugihara, M. Tsuchimori, O. Watanabe, H. Fujimura, and N. Okamoto, "Visible-laser ablation on a nanometer scale using urethane-urea copolymers," Optics Communications 157, 150 - 154 (1998).

[93] M. S. Silverstein, I. Visoly, O. Kesler, M. Janai, and Y. Cassuto, "Plasma polymer films for $532 \mathrm{~nm}$ laser micromachining," Journal of Vacuum Science \& Technology B 16, 2957-2967 (1998).

[94] S. Popov, "Dye photodestruction in a solid-state dye laser with a polymeric gain medium," Appl. Opt. 37, 6449-6455 (1998).

[95] D. Jacquemin, J. Preat, M. Charlot, V. Wathelet, J.-M. André, and E. A. Perpète, "Theoretical investigation of substituted anthraquinone dyes," The Journal of Chemical Physics 121, 1736-1743 (2004).

[96] D. Jacquemin, V. Wathelet, J. Preat, and E. A. Perpète, "Ab initio tools for the accurate prediction of the visible spectra of anthraquinones," Spectrochimica Acta Part A: Molecular and Biomolecular Spectroscopy 67, $334-$ 341 (2007).
[97] J. Fabian, "Tddft-calculations of vis/nir absorbing compounds," Dyes and Pigments 84, 36 - 53 (2010).

[98] D. Jacquemin, E. Brémond, A. Planchat, I. Ciofini, and C. Adamo, "TD-DFT vibronic couplings in anthraquinones: From basis set and functional benchmarks to applications for industrial dyes," Journal of Chemical Theory and Computation 7, 1882-1892 (2011).

[99] D. Jacquemin, A. Planchat, C. Adamo, and B. Mennucci, "TD-DFT assessment of functionals for optical 0-0 transitions in solvated dyes," Journal of Chemical Theory and Computation 8, 2359-2372 (2012).

[100] C. R. Company, CRC handbook of chemistry and physics (Online) (Boca Raton, Fla. : CRC Press : Taylor \& Francis, 1978), electronic ed.

[101] B. F. Howell and M. Kuzyk, "Lasing action and photodegradation of disperse orange 11 dye in liquid solution," Applied Physics Letters 85, 1901-1903 (2004).

[102] H. Nagai, H. Watanabe, and A. Nishioka, "Infrared spectra of deuterated polymethyl methacrylates," Journal of Polymer Science 62, S95-S98 (1962).

[103] H. Nagai, "Infrared spectra of stereoregular polymethyl methacrylate," Journal of Applied Polymer Science 7, 1697-1714 (1963).

[104] H. Willis, V. Zichy, and P. Hendra, "The laser-raman and infra-red spectra of poly(methyl methacrylate)," Polymer 10, 737 - 746 (1969).

[105] R. Silverstein and F. Webster, Spectrometric identification of organic compounds (John Wiley \& Sons, 1998), 6 th ed.

[106] J. Workman, Handbook of Organic Compounds: UV-Vis and NIR spectra, vol. 1 (Academic press, 2001).

[107] B. Schneider, J. Štokr, P. Schmidt, M. Mihailov, S. Dirlikov, and N. Peeva, "Stretching and deformation vibrations of $\mathrm{CH} 2, \mathrm{C}(\mathrm{CH} 3)$ and $\mathrm{O}(\mathrm{CH} 3)$ groups of poly(methyl methacrylate)," Polymer 20, 705 - 712 (1979).

[108] M. S. C. Flett, "The application of infra-red spectroscopy to structural problems in the anthraquinone field," J. Chem. Soc. pp. 1441-1448 (1948).

[109] D. Lin-Vien, N. B. Colthup, W. G. Fateley, and J. G. Grasselli, The handbook of infrared and Raman characteristic frequencies of organic molecules (Elsevier, 1991).

[110] F. M. Fowkes, D. O. Tischler, J. A. Wolfe, L. A. Lannigan, C. M. Ademu-John, and M. J. Halliwell, "Acidbase complexes of polymers," Journal of Polymer Science: Polymer Chemistry Edition 22, 547-566 (1984).

[111] P. Linstrom and W. Mallard, eds., NIST Mass Spec Data Center, S.E. Stein, director, "Infrared Spectra" in NIST Chemistry WebBook, NIST Standard Reference Database Number 69 (National Institute of Standards and Technology, Gaithersburg MD, 20899, retrieved February 5, 2015). Http://webbook.nist.gov.

[112] K. Pan, E. Boulais, L. Yang, and M. Bathe, "Structurebased model for light-harvesting properties of nucleic acid nanostructures," Nucleic acids research 42, 2159$2170(2014)$. 